\title{
Contribuições da assistência de enfermagem na prevenção de quedas e fraturas na atenção a saúde do idoso
}

Contributions of nursing care in the prevention of falls and fractures in health care for the elderly Contribuciones del cuidado de enfermería en la prevención de caídas y fracturas en el cuidado de la salud del adulto mayor

Mariana Pereira Barbosa Silva

ORCID: https://orcid.org/0000-0003-0852-8099 Universidade Estadual do Piauí, Brasil E-mail: marianapbsilvaa@gmail.com

Rayssa Stéfani Sousa Alves

ORCID: https://orcid.org/0000-0002-9666-675X Pontifícia Universidade Católica de Goiás, Brasil

E-mail: rayssastefani02@gmail.com

Marciele de Lima Silva

ORCID: https://orcid.org/0000-0003-2827-5316 Instituto de Educação Superior da Paraíba, Brasil

E-mail: marcieledelsilva@gmail.com

Bárbara Pereira Gomes

ORCID: https://orcid.org/0000-0002-0590-2228

Centro Universitário Unifacid Wyden, Brasil

E-mail: barbaraenfgomes@gmail.com

Danielle Sousa Almeida

ORCID: https://orcid.org/0000-0002-0537-8972

Centro Universitário Santo Agostinho, Brasil

E-mail: daniellyalmeida99@gmail.com

Flávia Nunes Barbosa

ORCID: https://orcid.org/0000-0002-8101-2032

Universidade Federal do Piauí, Brasil

E-mail: flavianunes-cat@hotmail.com

Juliana Torres Avelino

ORCID: https://orcid.org/0000-0002-8732-1856

Centro Universitário Santo Agostinho, Brasil

E-mail: Juliana_avelinno@hotmail.com

Vanessa Bonfim Mendes

ORCID: https://orcid.org/0000-0001-6228-3796

Centro Universitário Santo Agostinho, Brasil

E-mail: vbmcristao18@hotmail.com

Marilia Alves do Nascimento Santos

ORCID: https://orcid.org/0000-0002-5741-1818

Centro Universitário Unifacid Wyden, Brasil E-mail: maralves0088@gmail.com

Maria Rosemary da Silva Gomes

ORCID: https://orcid.org/0000-0002-8217-3647

Centro Universitário Santo Agostinho, Brasil

E-mail: mariarosemary2010@gmail.com

Erica Williams de Moreira Lima

ORCID: https://orcid.org/0000-0003-3957-5699

Centro Universitário Uninovafapi, Brasil

E-mail: williams-erica1992@outlook.com

Jessyca Thayane de Sousa Oliveira ORCID: https://orcid.org/0000-0002-1714-5981

Universidade Estadual do Maranhão, Brasil E-mail: jesthayane@gmail.com

Shandallyane Ludce Pinheiro de Farias ORCID: https://orcid.org/0000-0002-9180-6733

Centro Universitário Santo Agostinho, Brasil E-mail: ludcepinheiro@ hotmail.com 


\author{
Márcia Bethania de Sousa Silva \\ ORCID: https://orcid.org/0000-0001-5059-7528 \\ Centro Universitário Santo Agostinho, Brasil \\ E-mail: marcia-bethania@ hotmail.com \\ Rael Lourenço Barbosa Marinho \\ ORCID: https://orcid.org/0000-0002-4428-7627 \\ Centro Universitário Santo Agostinho, Brasil \\ E-mail: ra_el10@hotmail.com \\ Layanne Cavalcante de Moura \\ ORCID: https://orcid.org/0000-0003-2781-1076 \\ Centro Universitário Unifacid Wyden, Brasil \\ E-mail: layannecavalcante@ hotmail.com \\ Joelma Maria dos Santos da Silva Apolinário \\ ORCID: https://orcid.org/0000-0001-9521-9432 \\ Faculdade Maurício de Nassau, Brasil \\ E-mail: jo.silva00@hotmail.com \\ Gustavo Baroni Araujo \\ ORCID: https://orcid.org/0000-0002-3162-7477 \\ Universidade Estadual de Londrina, Brasil \\ E-mail: gustavobaroni13@hotmail.com \\ Tércio Macêdo de Andrade \\ ORCID: https://orcid.org/0000-0002-7441-4447 \\ Centro Universitário Maurício de Nassau, Brasil \\ E-mail: tercio.andrade@hotmail.com
}

\begin{abstract}
Resumo
Analisar as evidências científicas publicadas acerca das contribuições da assistência de enfermagem na prevenção de quedas e fraturas na atenção a saúde do idoso. O presente estudo trata de uma revisão bibliográfica do método revisão integrativa da literatura, realizado nos meses entre novembro de 2020 a janeiro de 2021. A busca efetuou-se, através da - BVS, utilizando as bases de dados LILACS, BDENF, e por meio da SCIELO. Aderindo-se através dos descritores/palavras chaves: "Cuidados de enfermagem", "Idoso", "Acidentes por quedas", combinados com o operador booleano "AND". Os enfermeiros realizam ações de cuidados, através do conhecimento dos fatores de riscos e da implementação das ações de prevenção para as quedas em idosos e ações de cuidados imediatos. O profissional de enfermagem, junto com a equipe multidisciplinar, deve ter a visão holística do paciente idoso, portanto o enfermeiro tem que observar o teórico e prático como analisar os fatores de risco para ter embasamento cientifico, como, na Atenção Básica de Saúde, projetar cuidados para cada caso desde orientações plano estratégico de ambiente seguro, utilização de dispositivos auxiliares, medicações utilizadas, analisar o risco e beneficio entre diversas necessidades. A partir da identificação do risco da queda pelo enfermeiro, ele poderá formular um plano de ação e, posteriormente, avaliar os resultados da assistência prestada. Diante desse contexto, as quedas em pacientes idosos acarretam traumas físicos, psicológicos, perda de independência e até mesmo do risco de morte. Dessa forma, é imperativo que profissionais da Enfermagem tenham conhecimento dos fatores de risco para a ocorrência deste evento.
\end{abstract}

Palavras-chave: Cuidados de enfermagem; Idoso; Acidentes por quedas.

\begin{abstract}
Analyze the published scientific evidence about the contributions of nursing care to the prevention of falls and fractures in the health care of the elderly. The present study deals with a bibliographic review of the integrative literature review method, carried out between November 2020 and January 2021. The search was carried out, through the - VHL, using the LILACS, BDENF databases, and through from SCIELO. Adhering to the descriptors / keywords: "Nursing care", "Elderly", "Accidents due to falls", combined with the Boolean operator "AND". Nurses carry out care actions, through the knowledge of risk factors and the implementation of preventive actions for falls in the elderly and immediate care actions. The nursing professional, along with the multidisciplinary team, must have a holistic view of the elderly patient, so the nurse has to observe the theoretical and practical how to analyze the risk factors to have a scientific basis, such as, in Primary Health Care, designing care for each case from guidelines for a safe environment strategic plan, use of auxiliary devices, medications used, analyzing the risk and benefit among different needs. From the identification of the risk of falling by the nurse, he will be able to formulate an action plan and, later, evaluate the results of the assistance provided. In this context, falls in elderly patients cause physical and psychological trauma, loss of independence and even the risk of death. Thus, it is imperative that nursing professionals are aware of the risk factors for the occurrence of this event.
\end{abstract}

Keywords: Nursing care; Old man; Accidents due to falls.

\title{
Resumen
}

Analizar la evidencia científica publicada sobre las contribuciones de los cuidados de enfermería a la prevención de caídas y fracturas en el cuidado de la salud del anciano. El presente estudio trata de una revisión bibliográfica del 
método de revisión integradora de la literatura, realizada entre noviembre de 2020 y enero de 2021. La búsqueda se realizó, a través de la BVS, utilizando las bases de datos LILACS, BDENF y SCIELO. Siguiendo los descriptores / palabras clave: "Atención de enfermería", "Anciano", "Accidentes por caídas", combinado con el operador booleano "Y". Los enfermeros realizan acciones asistenciales, a través del conocimiento de los factores de riesgo y la implementación de acciones preventivas de caídas en el anciano y acciones de atención inmediata. El profesional de enfermería, junto con el equipo multidisciplinario, debe tener una visión holística del paciente anciano, por lo que el enfermero debe observar lo teórico y práctico cómo analizar los factores de riesgo para tener una base científica, como en Atención Primaria de Salud, diseñar la atención para cada caso a partir de lineamientos para un plan estratégico de ambiente seguro, uso de dispositivos auxiliares, medicamentos utilizados, analizando el riesgo y beneficio entre las diferentes necesidades. A partir de la identificación del riesgo de caída por parte del enfermero, podrá formular un plan de acción y, posteriormente, evaluar los resultados de la asistencia brindada. En este contexto, las caídas en pacientes ancianos provocan traumas físicos y psicológicos, pérdida de la independencia e incluso riesgo de muerte. Por ello, es imperativo que los profesionales de enfermería conozcan los factores de riesgo para la ocurrencia de este evento.

Palabras clave: Cuidado de enfermera; Anciano; Accidentes por caídas.

\section{Introdução}

O envelhecimento da população é um fenômeno na sociedade mundial e vem tomando proporções significativas especialmente nos países em desenvolvimento. Percebe-se que, desde 1940, as taxas de mortalidade têm diminuído, em especial, entre as pessoas mais jovens. Assim, a expectativa de vida passou de 50 para 73 anos refletindo no aumento da população idosa. Estima-se que 25\% da população seja composta de idosos em 2050 (Oliveira et al., 2018). O aumento da população idosa no país traz, como consequência, a mudança no perfil das necessidades sanitárias, uma vez que as doenças que acometem indivíduos na terceira idade são, na maioria das vezes, crônico-degenerativas, distúrbios mentais, doenças cardiovasculares, câncer e estresse. Assim, têm produzido impacto importante em todos os níveis de atenção à saúde, dentre eles, o nível terciário, devido às internações hospitalares de pacientes idosos (Oliveira, 2017).

O processo de envelhecer é influenciado por diversos fatores, entre eles as doenças crônicas e os eventos adversos onde se destaca o evento quedas. A ocorrência de quedas é um indicador da perda da postura e da alteração de marcha, estando relacionada à insuficiência súbita de mecanismos neurais e osteomioarticulares. As quedas têm como definição, a ida a uma superfície de contato, a um nível inferior ao que estava anteriormente, sendo este um contato não intencional, resultante da perda de equilíbrio postural, sem que tenha havido um acidente inevitável ou perda de consciência. As mesmas podem ser originadas tanto por fatores intrínsecos, como as alterações fisiológicas do envelhecimento, doenças crônicas e a polifarmácia; quanto por fatores extrínsecos, geralmente os quais são decorrentes de circunstâncias socioambientais. O reconhecimento da multifatorialidade associada às quedas auxilia no esclarecimento dos fenômenos causais e consequentemente, nas medidas preventivas (Carvalho et al., 2019).

No Brasil, as quedas vêm se destacando entre as causas externas com grande impacto no perfil de mortalidade na população e ampla relevância na morbidade. Assim, é importante que o Enfermeiro saiba identificar os fatores de riscos para poder prevenir e posteriormente tratar as eventuais consequências das quedas (Carvalho et al., 2019). As quedas podem ocasionar diferentes consequências, desde lesões leves, até fraturas e morte, e causam impacto nas instituições de saúde ao aumentar o uso de recursos pessoais e materiais devido aos atendimentos médicos e de Enfermagem. Dessa forma, as quedas são consideradas a lesão de maior custo entre os idosos (Oliveira et al., 2018).

Após a queda, além das consequências diretas, as pessoas idosas restringem suas atividades devido às dores presentes, incapacidades, atitudes protetoras de familiares e cuidadores ou até mesmo por aconselhamento de profissionais de saúde não capacitados, gerando uma preocupação a respeito da possibilidade de cair. Este sentimento é definido como baixa autoeficácia ou confiança no próprio equilíbrio para evitar quedas, causando declínio no desempenho físico e funcional, alterações no equilíbrio e na marcha e impacto negativo na qualidade de vida, podendo ocasionar até mesmo a depressão. Nesta perspectiva, evitar o evento queda, assim como a preocupação na possibilidade de cair, atualmente é considerado uma conduta que requer o 
desenvolvimento de estratégias de prevenção, as quais são consideradas potencialmente úteis. Assim, atividades como melhorar a iluminação do ambiente, evitar tapetes soltos no domicílio e atentar para efeitos colaterais de diversas medicações são práticas que contribuem para a vigilância e prevenção de quedas (Araújo, Martins, Lima, \& Costa, 2016).

Segundo Ferreira e Yoshitome (2010), além da alta mortalidade, deve-se considerar outras consequências para a saúde e a qualidade de vida dos idosos como declínio da capacidade funcional, limitação na realização de atividade física, diminuição da mobilidade, receio de sofrer novas quedas, isolamento social, perda da autonomia e da independência para execução das atividades de vida diária.

Entre as principais causas de morbidade e mortalidade na população idosa encontram-se as quedas. Aproximadamente $30 \%$ das pessoas com mais de 65 anos e metade das com mais de 80 anos sofrem uma queda a cada ano. Em estudo realizado no Brasil, de 1996 a 2005, as mortes por causas externas levaram a óbito 41.054 idosos. Dessas, 9.249 (22,5\%) foram codificadas como quedas. A etiologia das quedas pode ser variada. Os fatores podem estar relacionados à pessoa, como o uso de fármacos, o medo de cair, distúrbios na caminhada, redução das atividades da vida diária ou a fatores relacionados ao ambiente como tapetes soltos, diferenças de nível e pisos escorregadiços. Acredita-se ser essencial também identificar os fatores de risco extrínsecos de quedas em pacientes idosos com a finalidade de reconhecer precocemente os riscos existentes e, de imediato, eliminá-los ou diminuí-los utilizando medidas adequadas para a prevenção do incidente (Oliveira et al., 2018).

A prevenção de quedas está ligada diretamente ao cuidado com o paciente, principalmente, quando se trata da pessoa idosa, porque envolve conhecimentos, sentimentos, comportamentos e atitudes dos enfermeiros e equipe. Nesse sentido, a vigilância para a prevenção da ocorrência da queda deve ser também uma das prioridades da assistência de Enfermagem no momento da internação do paciente na instituição de saúde. A partir da identificação do risco da queda pelo enfermeiro, ele poderá formular um plano de ação e, posteriormente, avaliar os resultados da assistência prestada (Oliveira et al., 2017).

De acordo com Freitas, Santos, Hammerschmidt, Silva, e Pelzer (2011), ressalta-se que a queda, como evento multifatorial, deve ter seu foco de prevenção no ambiente seguro, e nos hábitos e atitudes do idoso que podem representar risco. Desta forma, a autonomia, a capacidade funcional e a independência são aspectos importantes a serem analisados na determinação das quedas.

A capacidade funcional aparece como um novo paradigma de saúde, exibindo um valor ideal para que o idoso possa viver de modo independente, obtendo-se a capacidade de tomar banho, vestir-se, realizar higiene pessoal, deambular de um local para outro, alimentar-se, manter a continência, preparar refeições, administrar-se financeiramente, ingerir remédios, arrumar a casa, fazer compras, usar transporte coletivo, usar telefone e caminhar uma certa distância; ou seja, tendo esta a capacidade do indivíduo realizar suas atividades tanto físicas quanto mentais que são necessárias para manutenção de suas atividades básicas. Desse modo, a perda dessa capacidade está associada a um prognóstico de fragilidade, dependência, institucionalização, risco elevado de quedas, morte e problemas de mobilidade, trazendo complicações ao longo do tempo, e gerando cuidados de longa permanência e alto custo (Horta, Faria, \& Fernandes, 2016).

As pessoas idosas costumam apresentar perda progressiva da aptidão geral, como consequência do sedentarismo prolongado ou da hipocinesia, movimentos diminuídos ou lentos da musculatura do corpo, induzida por doenças, podendo comprometer seriamente a capacidade de realizar atividades diárias, dificultando a locomoção, aumentando os riscos de quedas e criando situações de risco cardiovascular nos esforços habituais. Com o aumento da idade cronológica ocorrem algumas alterações, tais como a mudança no peso, na estatura e na composição corporal. Apesar da importância do componente genético na determinação do peso e da estatura dos indivíduos, outros fatores influenciam nessas alterações, como a dieta, a atividade física, a interação social entre outros (Horta, Faria, \& Fernandes, 2016).

Vale destacar que as condições de risco que conduzem ao evento queda, podem ser multifatoriais e envolvem condições intrínsecas e extrínsecas. Entende-se por fatores intrínsecos aqueles decorrentes das alterações fisiológicas 
relacionadas ao avançar da idade. Os fatores extrínsecos, por sua vez, estão relacionados a ambientes inseguros, mal planejados e mal construídos, com barreiras arquitetônicas, presença de escadas, ausência de diferenciação de degraus e corrimãos, iluminação inadequada, tapetes soltos, obstáculos (fios elétricos, pisos mal conservados, por exemplo) no local de circulação. A identificação precoce e correta dos principais fatores de risco para quedas converge à possibilidade de prevenção desse agravo. Ao identificar os riscos de forma eficiente, pode-se evitar complicações resultantes da queda, como necessidade de intervenções de saúde e aumento da dependência física, além de ônus financeiro para o sistema de saúde (Costa et al., 2013).

Diante da temática em discussão, surge como questão norteadora do estudo: "Quais as contribuições da assistência de enfermagem na prevenção de quedas e fraturas na atenção a saúde do idoso"? Assim, o objetivo do presente estudo é analisar as evidências científicas publicadas acerca das contribuições da assistência de enfermagem na prevenção de quedas e fraturas na atenção a saúde do idoso.

A realização do estudo relacionado à temática, é essencial para a construção coletiva do conhecimento, pois, o estudo possibilita a sociedade acadêmica e cientifica a ampliar o conhecimento sobre as contribuições da assistência de enfermagem na prevenção de quedas e fraturas na atenção à saúde do idoso. Desse modo, o estudo trará contribuições importantes para a comunidade científica e para a sociedade, na medida em que acrescentará as evidências científicas discussões relevantes a respeito dessa temática tão importante. Desta forma, acredita-se que, o conhecimento das consequências físicas, psicológicas e sociais das quedas em idosos é de extrema importância, pois, o mesmo auxiliará no delineamento das estratégias preventivas e de reabilitação de tais repercussões.

\section{Metodologia}

O presente estudo trata de uma revisão bibliográfica do método revisão integrativa da literatura, realizado nos meses entre novembro de 2020 a janeiro de 2021. A revisão configura-se, portanto, como um tipo de revisão da literatura que reúne achados de estudos desenvolvidos mediante diferentes metodologias, permitindo aos revisores sintetizar resultados sem ferir a filiação epistemológica dos estudos empíricos incluídos. Para que esse processo concretize-se de maneira lógica, isenta de desatinos epistemológicos, a revisão requer que os revisores procedam à análise e à síntese dos dados primários de forma sistemática e rigorosa (Soares et al., 2014).

A revisão da literatura serve para reconhecer a unidade e a diversidade interpretativa existente no eixo temático em que se insere o problema em estudo, para ampliar, ramificar a análise interpretativa, bem como para compor as abstrações e sínteses que qualquer pesquisa requer colaborando para a coerência nas argumentações do pesquisador. Nesse sentido, a revisão integrativa é um método que tem como finalidade reunir e sintetizar resultados de pesquisas sobre um delimitado tema ou questão, de maneira sistemática e ordenada e abrangente, contribuindo para o aprofundamento do conhecimento do tema investigado (Ferenhof \& Fernandes, 2016).

O processo de revisão da literatura requer a elaboração de uma síntese pautada em diferentes tópicos, capazes de criar uma ampla compreensão sobre o conhecimento. A revisão da literatura é um primeiro passo para a construção do conhecimento científico, pois é através desse processo que novas teorias surgem, bem como são reconhecidas lacunas e oportunidades para o surgimento de pesquisas num assunto específico (Botelho, Cunha, \& Macedo, 2011).

A revisão integrativa é uma ferramenta de investigação que permite à procura, a avaliação crítica e a síntese de evidências disponíveis sobre o tema investigado, em que o produto final é o estado do conhecimento, a implementação de intervenções efetivas na prestação de cuidados e na redução de custos. Além disso, permite a identificação de fragilidades, que poderão conduzir ao desenvolvimento de futuras investigações (Sousa, Marques-Vieira, Severino, \& Antunes, 2017).

A revisão integrativa permite que o leitor reconheça os profissionais que mais investigam determinado assunto, separar o achado científico de opiniões e ideias, além de descrever o conhecimento no seu estado atual, promovendo impacto 
sobre a prática clínica. Este método de pesquisa proporciona aos profissionais de saúde dados relevantes de um determinado assunto, em diferentes lugares e momentos, mantendo-os atualizados e facilitando as mudanças na prática clínica como consequência da pesquisa. Dessa forma, acreditamos que a revisão integrativa é uma ferramenta importante no processo de comunicação dos resultados de pesquisas, facilitando a utilização desses na prática clínica, uma vez que proporciona uma síntese do conhecimento já produzido e fornece subsídios para a melhoria da assistência à saúde (Mendes, Silveira, \& Galvão, 2008)

Figura 1. Fluxograma fases distintas da revisão integrativa.

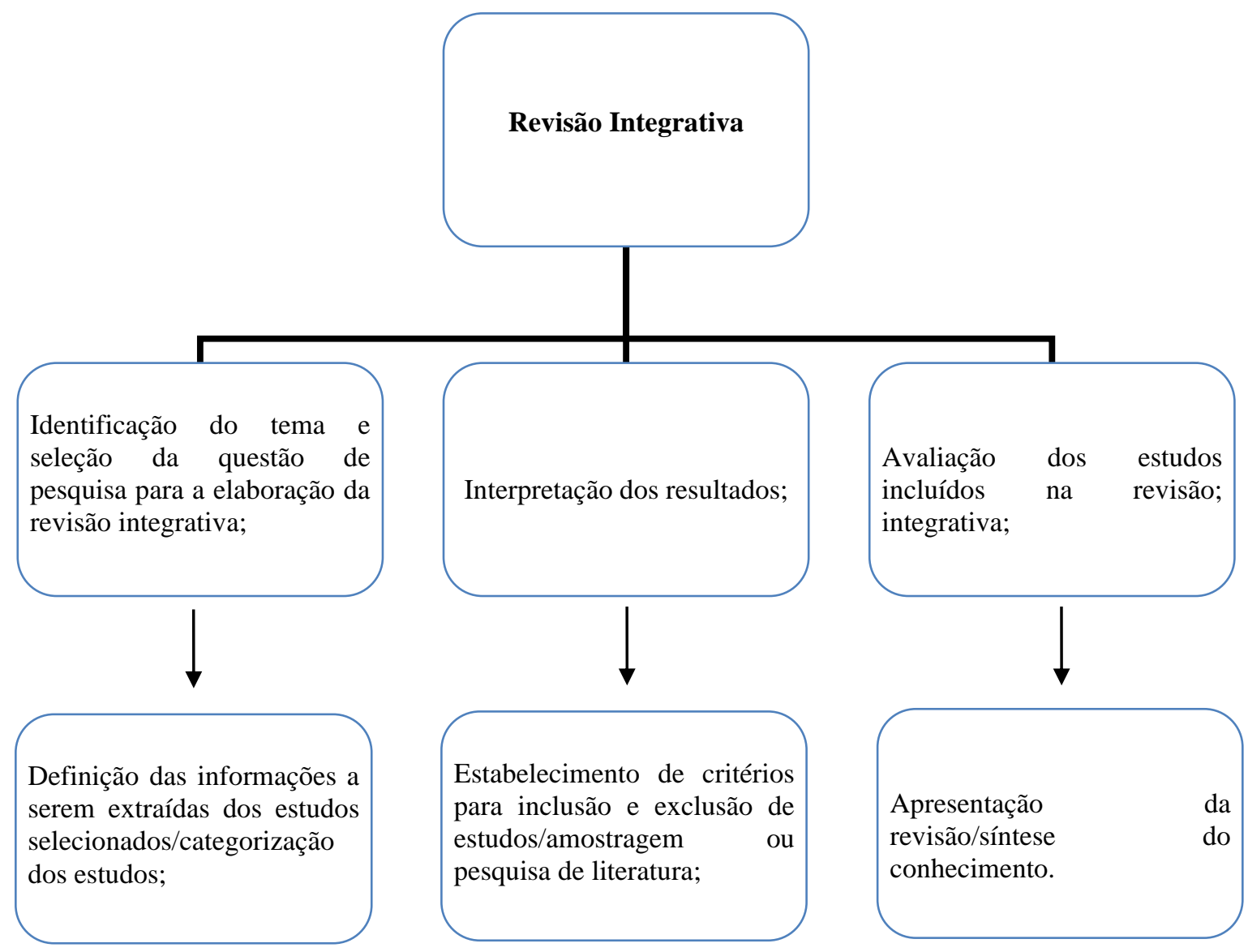

Fonte: Mendes, Silveira, \& Galvão (2008).

A revisão integrativa é um tipo de pesquisa que fornece informações mais amplas de maneira sistemática, ordenada e abrangente, sobre um assunto ou tema, com a finalidade de sintetizar resultados obtidos em pesquisa sobre temas ou questões. A definição das informações a serem extraídas dos estudos selecionados por categorização; avaliação dos estudos incluídos; interpretação dos resultados; e apresentação da revisão/síntese do conhecimento (Ercole, Melo, \& Alcoforado, 2015).

Estudo elaborado com abordagem qualitativa tornando-se importante a interpretação por parte do pesquisador com suas opiniões sobre o fenômeno em estudo. Neste tipo de pesquisa destacam-se algumas características como: a pesquisa qualitativa, em geral, ocorre no ambiente natural com coleta direta de dados e o pesquisador é o principal instrumento; os dados coletados são preferencialmente descritivos; a preocupação do processo é predominante em relação à do produto; a análise de dados e informações tende a seguir um processo indutivo (Pereira, Shitsuka, Parreira, \& Shitsuka, 2018).

A pesquisa qualitativa envolve uma abordagem interpretativa do mundo, o que significa que seus pesquisadores estudam as coisas em seus cenários naturais, tentando entender os fenômenos em termos dos significados que as pessoas a eles 
conferem. A pesquisa qualitativa atribui importância fundamental aos depoimentos dos atores sociais envolvidos, aos discursos e aos significados transmitidos por eles. Nesse sentido, esse tipo de pesquisa preza pela descrição detalhada dos fenômenos e dos elementos que o envolvem (Augusto, Souza, Dellagnelo, \& Cario, 2014).

De acordo com Souza, Silva, e Carvalho (2010), a ser realizada nas seguintes etapas: 1- Elaboração da pergunta norteadora; 2- Busca nas bases de dados e amostragem; 3- Coleta de dados, 4- Análise crítica.

Para responder à questão norteadora do estudo: "Quais as contribuições da assistência de enfermagem na prevenção de quedas e fraturas na atenção a saúde do idoso"? Aplicou-se os descritores/palavras-chaves: "Cuidados de enfermagem", "Idoso", "Acidentes por quedas".

A busca efetuou-se, através da Plataforma da Biblioteca Virtual em Saúde - BVS, utilizando as bases de dados Literatura Latino-Americana e do Caribe em Ciências da Saúde (LILACS), Base de Dados de Enfermagem (BDENF), e por meio da Biblioteca Eletrônica da Saúde - Scientific Electronic Library Online (SCIELO). Aderindo-se através dos descritores/palavras chaves: "Cuidados de enfermagem", "Idoso", "Acidentes por quedas", combinados com o operador booleano "AND".

Os critérios de inclusão estabelecidos foram: artigos originais disponibilizados na íntegra, completos, que abrangessem a temática e na forma online, publicados nos idioma português, inglês e espanhol, publicações que respondiam a questão norteadora do estudo. Os critérios de exclusão estabelecidos na seleção foram: artigos incompletos, artigos duplicados, teses, dissertações, monografias e manuais. No início da pesquisa obteve-se 21204 publicações, após a aplicação dos critérios de inclusão e exclusão totalizou-se parcialmente 176 artigos, depois de uma leitura mais precisa aderiu-se um total final de 24 publicações de acordo para serem trabalhadas no estudo.

O fluxograma representado abaixo, caracteriza a estratégia de coleta de dados utilizada pelos autores, no sentido de detalhar as principais evidencias encontradas no estudo. 
Figura 2. Fluxograma Estratégia de Busca - Bases de Dados, Teresina-PI, Brasil, 2021.

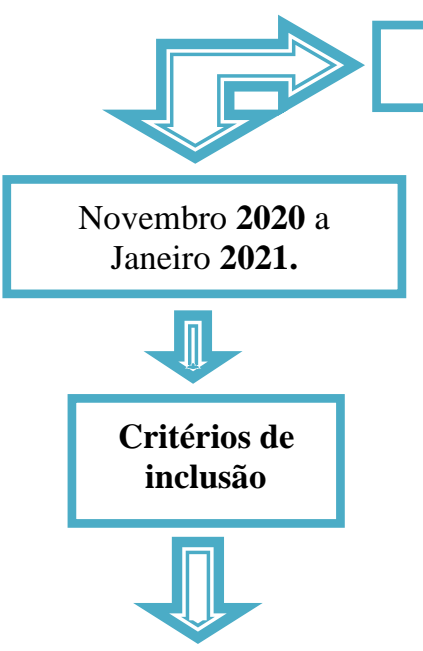

Artigos originais disponibilizados na íntegra, completos, que abrangessem a temática e na forma online, publicados nos idioma português, inglês e espanhol, publicações que respondiam a questão norteadora do estudo .

Estratégia de Busca Revisão Integrativa

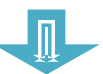

\section{Critérios de exclusão}
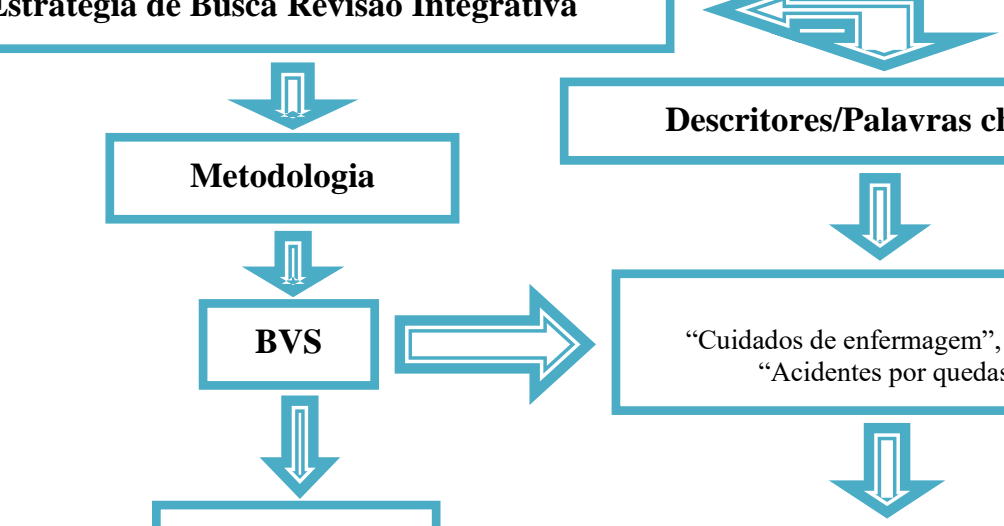

\section{Descritores/Palavras chaves:}

Bases de dados

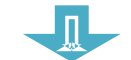

"AND"

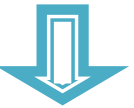

Artigos incompletos, artigos duplicados, teses, dissertações, monografias e manuais.
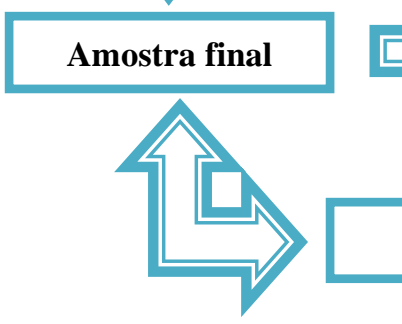

Amostra parcial

LILACS

BDENF

SCIELO
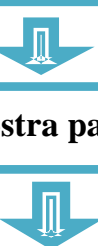

Fonte: Autores.

No Fluxograma 2, estão expostos, estratégia de busca, bases de dados, período de realização do estudo, critérios de inclusão e exclusão, amostra inicial, parcial e final, de acordo com a quantidade de artigos que irão compor os resultados do estudo.

O presente estudo assegura os aspectos éticos, garantindo a autoria dos artigos pesquisados, utilizando para as citações e referências dos autores as normas APA. Os preceitos éticos estabelecidos no que se refere a zelar pela legitimidade das informações, privacidade e sigilo das informações, quando necessárias, tornando os resultados desta pesquisa públicos. Os pesquisadores buscaram a legitimidade e fidelidade nas citações dos autores seja nas citações diretas ou parafraseadas no estudo. 


\section{Resultados e Discussão}

Diante dos resultados obtidos no estudo por meio da estratégia de busca, os autores delinearam variáveis para melhor descrever as evidências encontradas na pesquisa. O quadro a seguir caracteriza os artigos com base nas variáveis propostas: número do artigo, periódico, base de dados, autor e ano de publicação, título, objetivo, resultados em evidências e conclusões importantes.

Quadro 1. Artigos selecionados para o estudo.

\begin{tabular}{|c|c|c|c|c|c|c|}
\hline $\mathbf{N}$ & $\begin{array}{l}\text { Perió - } \\
\text { dico }\end{array}$ & $\begin{array}{c}\text { Bases } \\
\text { de } \\
\text { Dados }\end{array}$ & $\begin{array}{c}\text { Autor e } \\
\text { Ano }\end{array}$ & Título & Objetivo & $\begin{array}{l}\text { Resultados em evidências e } \\
\text { conclusões importantes }\end{array}$ \\
\hline 1 & $\begin{array}{l}\text { Rev } \\
\text { Baiana } \\
\text { Enferm }\end{array}$ & $\begin{array}{l}\text { LILA } \\
\text { CS }\end{array}$ & $\begin{array}{l}\text { Garollo } \\
\text { et al., } \\
2020 .\end{array}$ & $\begin{array}{l}\text { Cuidado e recuperação do } \\
\text { idoso com fratura } \\
\text { decorrente de queda na } \\
\text { perspectiva do cuidador } \\
\text { familiar. }\end{array}$ & $\begin{array}{l}\text { Apreender a perspectiva do } \\
\text { cuidador familiar sobre o } \\
\text { cuidado e a recuperação do } \\
\text { idoso com fratura decorrente de } \\
\text { queda. }\end{array}$ & $\begin{array}{l}\text { O cuidado e a recuperação do idoso com } \\
\text { fratura decorrente de queda é permeado por } \\
\text { dificuldades, em especial pela condição de } \\
\text { dependência do idoso, embora por vezes esta } \\
\text { seja temporária, pela dificuldade que o idoso } \\
\text { tem de aceitar esta condição, pela sobrecarga } \\
\text { física emocional, além das mudanças que } \\
\text { ocorrem em seu cotidiano pessoal e familiar. } \\
\text { Os cuidadores percebiam que a recuperação do } \\
\text { idoso com fratura decorrente de queda era } \\
\text { influenciada pelo esforço empreendido no } \\
\text { desempenho do cuidado, com vistas à } \\
\text { manutenção das atividades básicas de vida do } \\
\text { idoso e sua reabilitação. }\end{array}$ \\
\hline 2 & $\begin{array}{l}\text { Revista } \\
\text { Nur } \\
\text { sing }\end{array}$ & $\begin{array}{l}\text { LILA } \\
\text { CS }\end{array}$ & $\begin{array}{l}\text { Pereira, } \\
\text { Sá, } \\
\text { Napoleão } \\
\quad, \& \\
\text { Cavalcan } \\
\text { te, } 2020 .\end{array}$ & $\begin{array}{l}\text { Intervenções } r \text { de } \\
\text { enfermagem ao idoso } \\
\text { hospitalizado com risco de } \\
\text { queda. }\end{array}$ & $\begin{array}{l}\text { Comparar as intervenções de } \\
\text { enfermagem referentes ao risco } \\
\text { de queda no idoso } \\
\text { hospitalizado registradas nos } \\
\text { prontuários, com as } \\
\text { intervenções e as atividades } \\
\text { propostas pela NIC. }\end{array}$ & $\begin{array}{l}\text { Este estudo evidenciou as intervenções de } \\
\text { enfermagem de enfermagem registradas pelos } \\
\text { enfermeiros para idosos com riscos de quedas } \\
\text { registradas nos prontuários, com as } \\
\text { intervenções/atividades propostas pela NIC, } \\
\text { mediante a ferramenta metodológica do } \\
\text { mapeamento cruzado e constatou que as } \\
\text { intervenções semelhantes à NIC apresentavam } \\
\text { redigidas pelos enfermeiros. }\end{array}$ \\
\hline 3 & $\begin{array}{l}\text { Rev } \\
\text { Esc } \\
\text { Enferm } \\
\text { USP. }\end{array}$ & $\begin{array}{l}\text { LILA } \\
\text { CS }\end{array}$ & $\begin{array}{l}\text { Paula, } \\
\text { Gonçalve } \\
\text { s, } \\
\text { Nogueira } \\
\text {, \& } \\
\text { Delage, } \\
2020 .\end{array}$ & $\begin{array}{l}\text { Correlação entre } \\
\text { independência funcional e } \\
\text { risco de quedas em idosos } \\
\text { de três instituições de } \\
\text { longa permanência. }\end{array}$ & $\begin{array}{l}\text { Verificar a correlação entre a } \\
\text { independência funcional e o } \\
\text { risco de quedas em um grupo } \\
\text { de idosos institucionalizados. }\end{array}$ & $\begin{array}{l}\text { Para a prevenção de quedas, sugere-se que haja } \\
\text { um maior monitoramento nas ILPI em relação } \\
\text { aos idosos que já sofreram alguma queda, já } \\
\text { que esse evento é um preditor de novas } \\
\text { quedas. Portanto, recomenda-se às ILPIs a } \\
\text { adequação da estrutura do ambiente de modo a } \\
\text { torná-lo seguro, já que neste estudo, os lugares } \\
\text { que tiveram maior registro de quedas foram os } \\
\text { quartos e banheiros. Além disso, ressalta-se a } \\
\text { importância da educação continuada para os } \\
\text { profissionais de saúde e cuidadores, de forma a } \\
\text { capacitá-los na identificação de situações que } \\
\text { coloquem os idosos em risco de quedas. Por } \\
\text { fim, sugere-se ainda a realização de educação } \\
\text { em saúde com os idosos sobre os riscos de } \\
\text { queda, prevenção, importância do uso de } \\
\text { dispositivos de auxílio para locomoção e } \\
\text { realização de atividade física. }\end{array}$ \\
\hline 4 & $\begin{array}{l}\text { Rev } \\
\text { Enferm } \\
\text { UFPE } \\
\text { Online. }\end{array}$ & $\begin{array}{l}\mathrm{BDE} \\
\mathrm{NF}\end{array}$ & $\begin{array}{l}\text { Araújo et } \\
\text { al., } 2020 .\end{array}$ & $\begin{array}{l}\text { Incidentes relacionados à } \\
\text { assistência à saúde em } \\
\text { idosos hospitalizados. }\end{array}$ & $\begin{array}{lcr}\text { Analisar } & \text { notificações } & \text { de } \\
\text { incidentes } & \text { relacionados } & \text { à } \\
\text { assistência à saúde em idosos } \\
\text { hospitalizados. }\end{array}$ & $\begin{array}{l}\text { Tornam-se importantes as notificações dos } \\
\text { eventos adversos como fator de prevenção, } \\
\text { além de cooperar para a construção de um } \\
\text { banco de dados sobre riscos e situações- } \\
\text { problema. Consistem-se as notificações, } \\
\text { também, na execução de alterações necessárias } \\
\text { à assistência, o que proporciona um processo } \\
\text { de trabalho mais seguro e acautela futuros EA. } \\
\text { Permitir-se-á, pela catalogação e investigação } \\
\text { dessas ocorrências, a criação de programas de } \\
\text { educação permanente que instiguem o registro } \\
\text { das notificações e sustentem a segurança dos } \\
\text { usuários, incorrendo em melhoria contínua da } \\
\text { qualidade dos serviços de saúde. }\end{array}$ \\
\hline
\end{tabular}




\begin{tabular}{|c|c|c|c|c|c|c|}
\hline 5 & $\begin{array}{l}\text { Enferm } \\
\text { Foco }\end{array}$ & $\begin{array}{l}\text { LILA } \\
\text { CS }\end{array}$ & $\begin{array}{l}\text { Carvalho } \\
\text { et al., } \\
2019 .\end{array}$ & $\begin{array}{lr}\text { Evento quedas: } & \text { cuidados } \\
\text { de enfermagem } & \text { para a } \\
\text { segurança do do idoso } \\
\text { hospitalizado. }\end{array}$ & $\begin{array}{l}\text { Identificar os cuidados de } \\
\text { enfermagem, quanto ao evento } \\
\text { quedas, para a segurança de } \\
\text { idosos internados nas unidades } \\
\text { de internação de clínica } \\
\text { médica. }\end{array}$ & $\begin{array}{l}\text { Evidencia-se que os enfermeiros realizam } \\
\text { ações de cuidados, através do conhecimento } \\
\text { dos fatores de riscos e da implementação das } \\
\text { ações de prevenção para as quedas em idosos e } \\
\text { ações de cuidados imediatos, entretanto não } \\
\text { conhecem ou pouco utilizam ferramentas que } \\
\text { padronizem as ações e auxiliem nos cuidados } \\
\text { diários ao idoso com risco de quedas, bem } \\
\text { como a notificação. }\end{array}$ \\
\hline 6 & $\begin{array}{l}\text { Revista } \\
\text { Nur } \\
\text { sing }\end{array}$ & $\begin{array}{l}\text { BDE } \\
\text { NF }\end{array}$ & $\begin{array}{l}\text { Freire } e t \\
\text { al., } 2018 .\end{array}$ & $\begin{array}{l}\text { Conhecimento r dos } \\
\text { cuidadores de idosos } \\
\text { institucionalizados sobre } \\
\text { prevenção de quedas em } \\
\text { Fortaleza-CE. }\end{array}$ & $\begin{array}{l}\text { Avaliar o } \\
\text { cuidadores conhecimento dos } \\
\text { institucionalizados em relação à } \\
\text { prevenção de quedas. }\end{array}$ & $\begin{array}{l}\text { O cuidar é um exercício constante, que deve } \\
\text { considerar as particularidades do idoso e ser } \\
\text { pautado na formação e na educação continuada } \\
\text { promovidos por profissionais capacitados, } \\
\text { como o enfermeiro. O conhecimento sobre os } \\
\text { principais fatores de risco para a ocorrência de } \\
\text { quedas, e a detecção das concepção negativa } \\
\text { dos cuidadores de idosos sobre a prevenção } \\
\text { desses eventos devem fornecer subsídios para a } \\
\text { educação continuada dos profissionais } \\
\text { responsáveis pelo cuidado. }\end{array}$ \\
\hline 7 & $\begin{array}{l}\text { Rev } \\
\text { Enferm } \\
\text { UFPE } \\
\text { Online. }\end{array}$ & $\begin{array}{l}\mathrm{BDE} \\
\mathrm{NF}\end{array}$ & $\begin{array}{l}\text { Oliveira } \\
\text { et al., } \\
2018 .\end{array}$ & $\begin{array}{l}\text { Fatores extrínsecos para } \\
\text { risco de quedas de idosos } \\
\text { hospitalizados. }\end{array}$ & $\begin{array}{l}\text { Identificar os fatores } \\
\text { extrínsecos favoráveis à } \\
\text { ocorrência de quedas de } \\
\text { pacientes idosos hospitalizados. }\end{array}$ & $\begin{array}{l}\text { Acredita-se ser essencial também identificar os } \\
\text { fatores de risco extrínsecos de quedas em } \\
\text { pacientes idosos com a finalidade de } \\
\text { reconhecer precocemente os riscos existentes } \\
\text { e, de imediato, eliminá-los ou diminuí-los } \\
\text { utilizando medidas adequadas para a prevenção } \\
\text { do incidente. Logo, a relevância deste estudo } \\
\text { está na contribuição para a eficiência na } \\
\text { qualidade de atendimento e o conforto ao } \\
\text { paciente idoso hospitalizado. }\end{array}$ \\
\hline 8 & $\begin{array}{l}\text { Rev } \\
\text { Enferm } \\
\text { UFPE } \\
\text { Online. }\end{array}$ & $\begin{array}{l}\mathrm{BDE} \\
\mathrm{NF}\end{array}$ & $\begin{array}{l}\text { Oliveira } \\
\text { et al., } \\
2017 .\end{array}$ & $\begin{array}{l}\text { Avaliação de quedas em } \\
\text { idosos hospitalizados. }\end{array}$ & $\begin{array}{l}\text { Avaliar a ocorrência de queda } \\
\text { nos pacientes idosos internados } \\
\text { que apresentavam alto risco } \\
\text { para o evento. }\end{array}$ & $\begin{array}{l}\text { As quedas estão ligadas diretamente aos } \\
\text { indicadores de segurança do paciente, sendo } \\
\text { necessária uma abordagem multiprofissional e } \\
\text { interdisciplinar, avaliando os fatores de risco a } \\
\text { que os idosos hospitalizados estão expostos } \\
\text { para que sejam adotadas estratégias } \\
\text { preventivas para a manutenção da saúde. }\end{array}$ \\
\hline 9 & $\begin{array}{l}\text { Rev. } \\
\text { Eletr. } \\
\text { Enf. } \\
\text { [Intern } \\
\text { et]. }\end{array}$ & $\begin{array}{l}\text { LILA } \\
\text { CS }\end{array}$ & $\begin{array}{l}\text { Araújo, } \\
\text { Martins, } \\
\text { Lima, \& } \\
\text { Costa, } \\
2016 .\end{array}$ & $\begin{array}{l}\text { Preocupação com quedas } \\
\text { em pessoas idosas } \\
\text { atendidas em um Centro de } \\
\text { Atenção Integral. }\end{array}$ & $\begin{array}{l}\begin{array}{l}\text { Identificar } \\
\text { preocupação }\end{array} \text { nível de } \\
\text { relacionando-o com as doenças } \\
\text { autorreferidas e o histórico de } \\
\text { quedas dos idosos atendidos em } \\
\text { um Centro de Atenção Integral. }\end{array}$ & $\begin{array}{l}\text { É fundamental que políticas públicas e } \\
\text { institucionais de prevenção de quedas sejam } \\
\text { instituídas com urgência, para que o idoso não } \\
\text { tenha medo de cair ou que esse acontecimento } \\
\text { não se repita novamente. Acredita-se que, ao } \\
\text { possuir conhecimento sobre os fatores de risco } \\
\text { e as formas de prevenir a queda, o idoso } \\
\text { consiga compreender o evento e assim } \\
\text { diminuir a sua preocupaçãa com o cair. A } \\
\text { enfermagem deve estabelecer ações integrais } \\
\text { que contemplem o mapeamento do risco de } \\
\text { queda e uma conscientização desses idosos e } \\
\text { familiares quanto às formas de prevenção. }\end{array}$ \\
\hline 10 & $\begin{array}{l}\text { Rev } \\
\text { Bras } \\
\text { Enferm }\end{array}$ & $\begin{array}{l}\text { LILA } \\
\text { CS }\end{array}$ & $\begin{array}{l}\text { Freitas, } \\
\text { Santos, } \\
\text { Hammers } \\
\text { chmidt, } \\
\text { Silva, \& } \\
\text { Pelzer, } \\
2011 .\end{array}$ & $\begin{array}{l}\text { Cuidado de enfermagem } \\
\text { para prevenção de quedas } \\
\text { em idosos: proposta para } \\
\text { ação. }\end{array}$ & $\begin{array}{l}\text { Construir uma proposta de ação } \\
\text { de enfermagem para prevenção } \\
\text { de quedas em idosos. }\end{array}$ & $\begin{array}{l}\text { A proposta de ação de enfermagem } \\
\text { apresentada envolve mudanças de hábito dos } \\
\text { idosos como: reeducação alimentar, para uma } \\
\text { alimentação saudável; reorganização da } \\
\text { moradia, tornando o ambiente seguro; e } \\
\text { conhecimento do condicionamento físico, para } \\
\text { fortalecimento do sistema motor. Ressalta-se } \\
\text { que o enfermeiro pode auxiliar o idoso a } \\
\text { prevenir as quedas, estimulando aumento da } \\
\text { mobilidade, alimentação saudável e ambiente } \\
\text { seguro. }\end{array}$ \\
\hline 11 & $\begin{array}{l}\text { Rev } \\
\text { Bras } \\
\text { Enferm }\end{array}$ & $\begin{array}{l}\text { SCIE } \\
\text { LO }\end{array}$ & $\begin{array}{l}\text { Ferreira, } \\
\quad \& \\
\text { Yoshitom } \\
\text { e, } 2010 .\end{array}$ & $\begin{array}{l}\text { Prevalência e caraterísticas } \\
\text { das quedas de idosos } \\
\text { institucionalizados. }\end{array}$ & $\begin{array}{l}\text { Verificar a prevalência de } \\
\text { quedas em idosos residentes em } \\
\text { uma Instituição de Longa } \\
\text { Permanência localizada no } \\
\text { município de São Paulo; } \\
\text { Caracterizar os idosos que } \\
\text { sofreram quedas no período } \\
\text { estudado, com relação a } \\
\text { variáveis demográficas e } \\
\text { clínicas; Descrever as } \\
\text { características das quedas } \\
\text { ocorridas em relação a sua } \\
\text { frequência, causas, } \\
\text { circunstâncias e consequências. }\end{array}$ & $\begin{array}{l}\text { Evidencia-se que a prevalência de quedas em } \\
\text { idosos institucionalizados é elevada, sendo } \\
\text { mais frequente em mulheres de idade } \\
\text { avançada, as quais sofrem quedas recorrentes, } \\
\text { são portadoras de diversas patologias, fazendo } \\
\text { uso de vários medicamentos, apresentam } \\
\text { algum grau de déficit cognitivo e funcional e } \\
\text { locomovem-se com auxílio de bengala. Com } \\
\text { relação às quedas, estas se deram em sua } \\
\text { maioria pela manhã, da própria altura do idoso, } \\
\text { enquanto ele deambulava no seu próprio } \\
\text { quarto, gerando algum tipo de consequência } \\
\text { física para o idoso, sendo a mais comum os } \\
\text { hematomas/sangramentos. }\end{array}$ \\
\hline
\end{tabular}




\begin{tabular}{|c|c|c|c|c|c|c|}
\hline 12 & $\begin{array}{l}\text { Connec } \\
\text { ti } \\
\text { Online. }\end{array}$ & $\begin{array}{l}\text { SCIE } \\
\text { LO }\end{array}$ & $\begin{array}{l}\text { Horta, } \\
\text { Faria, \& } \\
\text { Fernande } \\
\text { s, } 2016 .\end{array}$ & $\begin{array}{l}\text { Quedas em idosos: } \\
\text { assistência de enfermagem } \\
\text { na prevenção. }\end{array}$ & $\begin{array}{l}\text { Conhecer as causas de quedas } \\
\text { em idosos, a fim de fortalecer a } \\
\text { assistência de enfermagem, } \\
\text { contribuindo para a prevenção } \\
\text { ou diminuição desta ocorrência } \\
\text { e consequentemente de óbitos. }\end{array}$ & $\begin{array}{l}\text { A suscetibilidade a quedas aumenta } \\
\text { relativamente com o número de fatores de } \\
\text { risco, cabendo aos profissionais de saúde, em } \\
\text { especial aos enfermeiros, atuar sobre os } \\
\text { mesmos. Estes profissionais devem direcionar } \\
\text { seu olhar à atenção, cuidado, incentivo e } \\
\text { valorização da história de vida do idoso. Esta } \\
\text { ação preventiva deve ser feita com o preparo } \\
\text { da casa para o idoso o orientação aos familiares } \\
\text { e cuidadores, dando atenção à detalhes que } \\
\text { evitem quedas e suas possíveis consequências, } \\
\text { promovendo assim, melhora na autonomia, } \\
\text { independência e autoconfiança do idoso. }\end{array}$ \\
\hline 13 & $\begin{array}{l}\text { Cogita } \\
\text { re } \\
\text { Enferm }\end{array}$ & $\begin{array}{l}\text { SCIE } \\
\text { LO }\end{array}$ & $\begin{array}{l}\text { Feliciani, } \\
\text { Santos, \& } \\
\text { Valcaren } \\
\text { ghi, } \\
2011 .\end{array}$ & $\begin{array}{l}\text { Funcionalidade e } \\
\text { em quedas } \\
\text { institucionalizados: pro - } \\
\text { postas de ações de } \\
\text { enfermagem. }\end{array}$ & $\begin{array}{l}\text { Propor ações de melhoria para } \\
\text { uma Instituição de Longa } \\
\text { Permanência para Idosos, que } \\
\text { auxiliem o enfermeiro na } \\
\text { manutenção da funcionalidade } \\
\text { e prevenção das quedas dos } \\
\text { idosos residentes. }\end{array}$ & $\begin{array}{l}\text { A ocorrência de queda em um idoso é uma } \\
\text { realidade acompanhada de inúmeras } \\
\text { consequências, algumas vezes irreversíveis, } \\
\text { podendo trazer dificuldades ou } \\
\text { impossibilidades para a realização das } \\
\text { Atividades de Vida Diária (AVD). Isto acarreta } \\
\text { problemas não só para os idosos, mas também } \\
\text { para suas famílias e para os serviços de saúde, } \\
\text { que mobilizam mais recursos no tratamento e } \\
\text { na reabilitação. }\end{array}$ \\
\hline 14 & $\begin{array}{l}\text { Rev } \\
\text { Bras } \\
\text { Geriatr } \\
\text { Geront } \\
\text { ol. }\end{array}$ & $\begin{array}{l}\text { SCIE } \\
\text { LO }\end{array}$ & $\begin{array}{l}\text { Maia, } \\
\text { Viana, } \\
\text { Arantes, } \\
\quad \& \\
\text { Alencar, } \\
2011 .\end{array}$ & $\begin{array}{l}\text { Consequências das quedas } \\
\text { em idosos vivendo na } \\
\text { comunidade. }\end{array}$ & $\begin{array}{l}\text { Investigar as consequências das } \\
\text { quedas em idosos vivendo na } \\
\text { comunidade. }\end{array}$ & $\begin{array}{l}\text { Pode-se concluir que a ocorrência de quedas } \\
\text { em idosos pode resultar em um relevante } \\
\text { problema de saúde. Constata-se que uma } \\
\text { grande variedade de consequências pode } \\
\text { ocorrer após um episódio de queda. Estas } \\
\text { podem envolver danos físicos, como lesões } \\
\text { teciduais, ferimentos e fraturas, declínio } \\
\text { funcional e aumento da dependência e questões } \\
\text { psicossociais, como medo de cair, isolamento e } \\
\text { perda da autonomia. Considerando a gravidade } \\
\text { de várias destas consequências, há necessidade } \\
\text { de programas eficazes de prevenção das } \\
\text { quedas. Além destes, também é importante a } \\
\text { implantação de programas de reabilitação após } \\
\text { as quedas, com o objetivo de impedir ou } \\
\text { minimizar a ocorrência de tais repercussões. }\end{array}$ \\
\hline 15 & $\begin{array}{l}\text { Rev } \\
\text { Rene. }\end{array}$ & $\begin{array}{l}\text { SCIE } \\
\text { LO }\end{array}$ & $\begin{array}{l}\text { Costa } e t \\
\text { al., } 2013 .\end{array}$ & $\begin{array}{l}\text { Fatores de risco para } \\
\text { quedas em idosos. }\end{array}$ & $\begin{array}{l}\text { Investigar os fatores de risco } \\
\text { intrínsecos e extrínsecos para } \\
\text { quedas em idosos e verificar a } \\
\text { existência de possíveis } \\
\text { associações estatísticas entre } \\
\text { grupos com e sem o relato de } \\
\text { queda nos últimos seis meses. }\end{array}$ & $\begin{array}{l}\text { Os fatores de risco intrínsecos ou individuais } \\
\text { tais como alterações nos pés, equilíbrio } \\
\text { prejudicado e déficit proprioceptivo foram os } \\
\text { mais relevantes no âmbito das quedas, ao } \\
\text { apresentarem maior significância estatística. } \\
\text { Vale ressaltar que estes fatores compõem um } \\
\text { sistema inter-relacionado em que a alteração } \\
\text { em um deles pode interferir diretamente no } \\
\text { outro, diminuindo o limiar das quedas, uma } \\
\text { vez que constituem um sistema responsável } \\
\text { pela manutenção do equilíbrio e sustentação do } \\
\text { corpo. }\end{array}$ \\
\hline 16 & $\begin{array}{l}\text { Ciencia } \\
\quad \& \\
\text { Saúde } \\
\text { Coleti } \\
\text { va. }\end{array}$ & $\begin{array}{l}\text { SCIE } \\
\text { LO }\end{array}$ & $\begin{array}{l}\text { Abreu, } \\
\text { Novaes, } \\
\text { Oliveira, } \\
\text { Mathias, } \\
\& \\
\text { Marcon, } \\
2018 . \\
\end{array}$ & $\begin{array}{lll}\text { Internação e mortalidade } \\
\text { por quedas em idosos no } \\
\text { Brasil: análise } \\
\text { tendência. }\end{array}$ & $\begin{array}{l}\text { Analisar a tendência temporal } \\
\text { das internações e da } \\
\text { mortalidade por quedas em } \\
\text { idosos, no Brasil e capitais dos } \\
\text { estados, no período de } 1996 \text { a } \\
2012 \text {. }\end{array}$ & $\begin{array}{l}\text { A cada ano, aumentam os gastos relacionados } \\
\text { ao atendimento de pessoas com lesões } \\
\text { decorrentes de quedas, uma vez que as taxas de } \\
\text { internação e mortalidade por quedas em idosos } \\
\text { se mostram em ascensão. No entanto, as taxas } \\
\text { de internação e mortalidade por quedas em } \\
\text { idosos variaram em relação ao sexo, e também } \\
\text { segundo a capital de residência }\end{array}$ \\
\hline 17 & $\begin{array}{c}\text { Braz J } \\
\text { Hea } \\
\text { Rev. }\end{array}$ & $\begin{array}{l}\text { SCIE } \\
\text { LO }\end{array}$ & $\begin{array}{l}\text { Oliveira, } \\
\text { Francisco } \\
\text {, Santos, } \\
\text { Cesar, \& } \\
\text { Lima, } \\
2019 .\end{array}$ & $\begin{array}{l}\text { Fatores de risco para } \\
\text { quedas em idosos no } \\
\text { domicilio: um olhar para a } \\
\text { prevenção. }\end{array}$ & $\begin{array}{l}\text { Conhecer os fatores de risco } \\
\text { para quedas de idosos no } \\
\text { domić́lio; Identificar ações que } \\
\text { podem ser realizadas pelo } \\
\text { enfermeiro na Atenção à Saúde } \\
\text { Domiciliar para prevenir } \\
\text { quedas de idosos. }\end{array}$ & $\begin{array}{l}\text { Os fatores de risco para quedas quando } \\
\text { identificados, sua prevenção torna-se viável, } \\
\text { para isso, é necessária a avaliação de riscos } \\
\text { ambientais, modificações fisiológicas do } \\
\text { envelhecimento e comportamentos individuais } \\
\text { e coletivos do idoso. No entanto em sua grande } \\
\text { maioria as ações relacionadas às quedas } \\
\text { encontradas atualmente, destinam-se ao } \\
\text { momento pós-evento, ou seja, ações focadas na } \\
\text { cura e reabilitação e não na prevenção, } \\
\text { enfatizando então a importância do presente } \\
\text { trabalho. }\end{array}$ \\
\hline
\end{tabular}




\begin{tabular}{|c|c|c|c|c|c|c|}
\hline 18 & $\begin{array}{l}\text { Braz J } \\
\text { Of } \\
\text { Develo } \\
\text { p. }\end{array}$ & $\begin{array}{l}\text { SCIE } \\
\text { LO }\end{array}$ & $\begin{array}{l}\text { Garcia et } \\
\text { al., } 2020 .\end{array}$ & $\begin{array}{l}\text { Educação em saúde na } \\
\text { prevenção de quedas em } \\
\text { idosos. }\end{array}$ & $\begin{array}{l}\text { Descrever a importância das } \\
\text { práticas de educação em saúde } \\
\text { junto às ações da atenção } \\
\text { básica para prevenção de } \\
\text { quedas em idosos. }\end{array}$ & $\begin{array}{l}\text { As consequências das quedas podem incluir } \\
\text { morbidade, mortalidade, deterioração } \\
\text { funcional, hospitalização e institucionalização. } \\
\text { Há restrição nas atividades cotidiana dos } \\
\text { idosos devido a dores, a incapacidades, ao } \\
\text { medo de cair, e por atitudes protetoras de } \\
\text { familiares e cuidadores. Além da alta } \\
\text { mortalidade, deve-se levar em consideração } \\
\text { outras consequências para a saúde e a } \\
\text { qualidade de vida dos idosos como declínio da } \\
\text { capacidade funcional, limitação na realização } \\
\text { de atividade física, diminuição da mobilidade, } \\
\text { receio de sofrer novas quedas, isolamento } \\
\text { social, perda da autonomia e da independência } \\
\text { para execução das atividades de vida diária }\end{array}$ \\
\hline 19 & $\begin{array}{l}\text { Portu } \\
\text { guese } \\
\text { Reon } \\
\text { Face } \\
\text { ma. }\end{array}$ & $\begin{array}{l}\text { SCIE } \\
\text { LO }\end{array}$ & $\begin{array}{l}\text { Lima, } \\
\text { Pessôa, } \\
\text { Almeida, } \\
\text { \& Penha, } \\
2017 .\end{array}$ & $\begin{array}{l}\text { Cuidados de enfermagem } \\
\text { na promoção da segurança } \\
\text { do idoso hospitalizado na } \\
\text { prevenção de quedas. }\end{array}$ & $\begin{array}{l}\text { Descrever as dificuldades } \\
\text { encontradas pelos enfermeiros } \\
\text { (as) na promoção da segurança } \\
\text { do idoso hospitalizado na } \\
\text { prevenção de quedas. }\end{array}$ & $\begin{array}{l}\text { O estudo procurou entender as dificuldades dos } \\
\text { enfermeiros em promover a segurança do idoso } \\
\text { hospitalizado na prevenção de quedas, e de } \\
\text { acordo com os dados coletados, percebeu-se o } \\
\text { quanto o enfermeiro possui dificuldades de } \\
\text { cuidar de pacientes idosos hospitalizados, } \\
\text { devido à falta de recursos humanos, estruturas } \\
\text { inadequadas como falta de materiais e } \\
\text { equipamentos, e a própria desvalorização } \\
\text { profissional. }\end{array}$ \\
\hline 20 & $\begin{array}{l}\text { Revista } \\
\text { Científi } \\
\text { ca } \\
\text { Eletrô } \\
\text { nica de } \\
\text { Ciênci } \\
\text { as } \\
\text { Aplica } \\
\text { das da } \\
\text { Fait. }\end{array}$ & $\begin{array}{l}\text { SCIE } \\
\text { LO }\end{array}$ & $\begin{array}{l}\text { Ferreira, } \\
\quad \& \\
\text { Almeida, } \\
2017 .\end{array}$ & $\begin{array}{l}\text { Risco de queda em idosos: } \\
\text { atuação da enfermagem na } \\
\text { prevenção. }\end{array}$ & $\begin{array}{l}\text { Apontar os principais fatores de } \\
\text { risco de queda em idosos }\end{array}$ & $\begin{array}{l}\text { As quedas têm alta proporção de acometer a } \\
\text { qualidade de vida do idoso, as consequências } \\
\text { têm grande impacto na vida da pessoa idosa } \\
\text { por serem muito graves em vista a de } \\
\text { indivíduos jovens, causam implicações para } \\
\text { família e ao risco que implicam na vida dos } \\
\text { mesmos. Em função de sua natureza, sua } \\
\text { frequência e suas consequências, as quedas } \\
\text { constituem uma das grandes síndromes } \\
\text { geriátricas e um dos maiores problemas de } \\
\text { saúde publica, além de estarem relacionados a } \\
\text { maior morbidade e mortalidade na velhice, } \\
\text { associam se a restrição na mobilidade, fraturas, } \\
\text { depressão, incapacidade funcional, perda da } \\
\text { independência e autonomia e declínio na } \\
\text { qualidade de vida. }\end{array}$ \\
\hline 21 & $\begin{array}{l}\text { Rev } \\
\text { Baiana } \\
\text { Enferm }\end{array}$ & $\begin{array}{l}\text { SCIE } \\
\text { LO }\end{array}$ & $\begin{array}{l}\text { Baixinho, } \\
\text { \& Dixe, } \\
2020 .\end{array}$ & $\begin{array}{l}\text { Quais as práticas dos } \\
\text { cuidadores para prevenir as } \\
\text { quedas nos idosos } \\
\text { institucionalizados. }\end{array}$ & $\begin{array}{l}\text { Descrever as práticas dos } \\
\text { cuidadores na gestão do risco } \\
\text { de queda de idosos } \\
\text { institucionalizados e relacionar } \\
\text { as práticas com a idade, } \\
\text { formação e tempo de exercício } \\
\text { profissional dos cuidadores. }\end{array}$ & $\begin{array}{l}\text { Sobressai para a prática à necessidade de os } \\
\text { enfermeiros, como líderes na gestão do risco } \\
\text { de queda, formar, treinar e monitorizar os } \\
\text { cuidadores no cuidado para a prevenção de } \\
\text { riscos de quedas em idosos institucionalizados. }\end{array}$ \\
\hline 22 & $\begin{array}{l}\text { ReBIS } \\
\text { [Intern } \\
\text { et]. }\end{array}$ & $\begin{array}{l}\text { SCIE } \\
\text { LO }\end{array}$ & $\begin{array}{l}\text { Queiroz, } \\
\text { Feitosa, } \\
\text { Rodrigue } \\
\text { s, \& } \\
\text { Sousa, } \\
2020 .\end{array}$ & $\begin{array}{l}\text { Intervenções na prevenção } \\
\text { de quedas de idosos em } \\
\text { ambiente domiciliar. }\end{array}$ & $\begin{array}{l}\text { Identificar os riscos de quedas } \\
\text { relacionados a fatores } \\
\text { extrínsecos, a propor } \\
\text { intervenções na promoção e } \\
\text { prevenção em saúde no âmbito } \\
\text { domiciliar. }\end{array}$ & $\begin{array}{l}\text { É função do enfermeiro, avaliar o histórico no } \\
\text { intuito de buscar maior riqueza de informações } \\
\text { para elaborar estratégias de prevenção e } \\
\text { consequentemente suas reincidências. } \\
\text { Conhecer esses dados permitirá a confecção de } \\
\text { um planejamento de forma mais eficaz e } \\
\text { satisfatória, respeitando a autonomia da pessoa } \\
\text { idosa e seu nível econômico, envolvendo a } \\
\text { família (se for o caso) no processo do cuidar, } \\
\text { promovendo a educação continuada desses } \\
\text { familiares e/ou cuidadores como apoio } \\
\text { fundamental a proteção à pessoa idosa. }\end{array}$ \\
\hline 23 & $\begin{array}{l}\text { Braz J } \\
\text { Hea } \\
\text { Rev. }\end{array}$ & $\begin{array}{l}\text { SCIE } \\
\text { LO }\end{array}$ & $\begin{array}{l}\text { Souza } e t \\
\text { al., } 2020 .\end{array}$ & $\begin{array}{l}\text { Concepções da equipe de } \\
\text { enfermagem sobre a } \\
\text { prevenção de quedas em } \\
\text { ambiente hospitalar. }\end{array}$ & $\begin{array}{l}\text { Conhecer a concepção de } \\
\text { profissionais de enfermagem } \\
\text { sobre os cuidados e orientações } \\
\text { prestadas para pacientes } \\
\text { hospitalizados quanto à } \\
\text { prevenção de quedas. }\end{array}$ & $\begin{array}{l}\text { As quedas são classificadas em três tipos: } \\
\text { acidental causada por fatores ambientais onde } \\
\text { o paciente escorrega ou tropeça; Queda } \\
\text { Fisiológica Antecipada, pode ser prevista por } \\
\text { meio da classificação da Escala de Morse e o } \\
\text { paciente demonstra sinais que indica a } \\
\text { probabilidade de cair; e, Queda Fisiológica não } \\
\text { Antecipada é associada a eventos clínicos4. } \\
\text { Tornam-se necessário classificar as quedas } \\
\text { para avaliar e definir estratégias de prevenção } \\
\text { adequadas para cada tipo. }\end{array}$ \\
\hline
\end{tabular}




\begin{tabular}{|c|c|c|c|c|c|c|}
\hline 24 & $\begin{array}{c}\text { Brazili } \\
\text { an J of } \\
\text { Develo } \\
\text { pment }\end{array}$ & $\begin{array}{l}\text { SCIE } \\
\text { LO }\end{array}$ & $\begin{array}{l}\text { Costa, } \\
\text { Porolnik, } \\
\text { Arruda, } \\
\text { Petter, \& } \\
\text { Pivetta, } \\
2021 .\end{array}$ & $\begin{array}{l}\text { Risco de quedas de idosas } \\
\text { fisicamente ativas. }\end{array}$ & $\begin{array}{l}\text { Analisar o risco de quedas de } \\
\text { idosas fisicamente ativas. }\end{array}$ & $\begin{array}{l}\text { Diante do envelhecimento populacional que } \\
\text { traz modificações nos fatores epidemiológicos, } \\
\text { sociais, econômicos e ambientais, percebe-se } \\
\text { que é preciso trabalhar em prol da prevenção e } \\
\text { promoção da saúde dessa população, pois } \\
\text { surgem desafios relacionados ao cuidado que } \\
\text { se faz cada vez maior. Existem alterações } \\
\text { orgânicas que são inerentes ao processo de } \\
\text { envelhecimento e que podem se tornar } \\
\text { obstáculos para o envelhecimento ativo e } \\
\text { saudável. }\end{array}$ \\
\hline
\end{tabular}

Fonte: Autores (2020).

No Quadro 1, tem-se a apresentação dos artigos selecionados para o estudo conforme número do artigo, periódico, base de dados, título, autor e ano de publicação, objetivo, resultados em evidências e conclusões importantes, com a finalidade de facilitar o desenvolvimento da discussão. A partir do estudo dos artigos estabeleceram-se discussões relevantes para observações das produções científicas relacionadas à pesquisa.

No gráfico a seguir, estão expostos os periódicos e a quantidade de artigos encontrados na seleção da amostra final dos artigos que serão trabalhados na elaboração do referido estudo.

Gráfico 1. Distribuição dos artigos conforme periódico e quantidade.

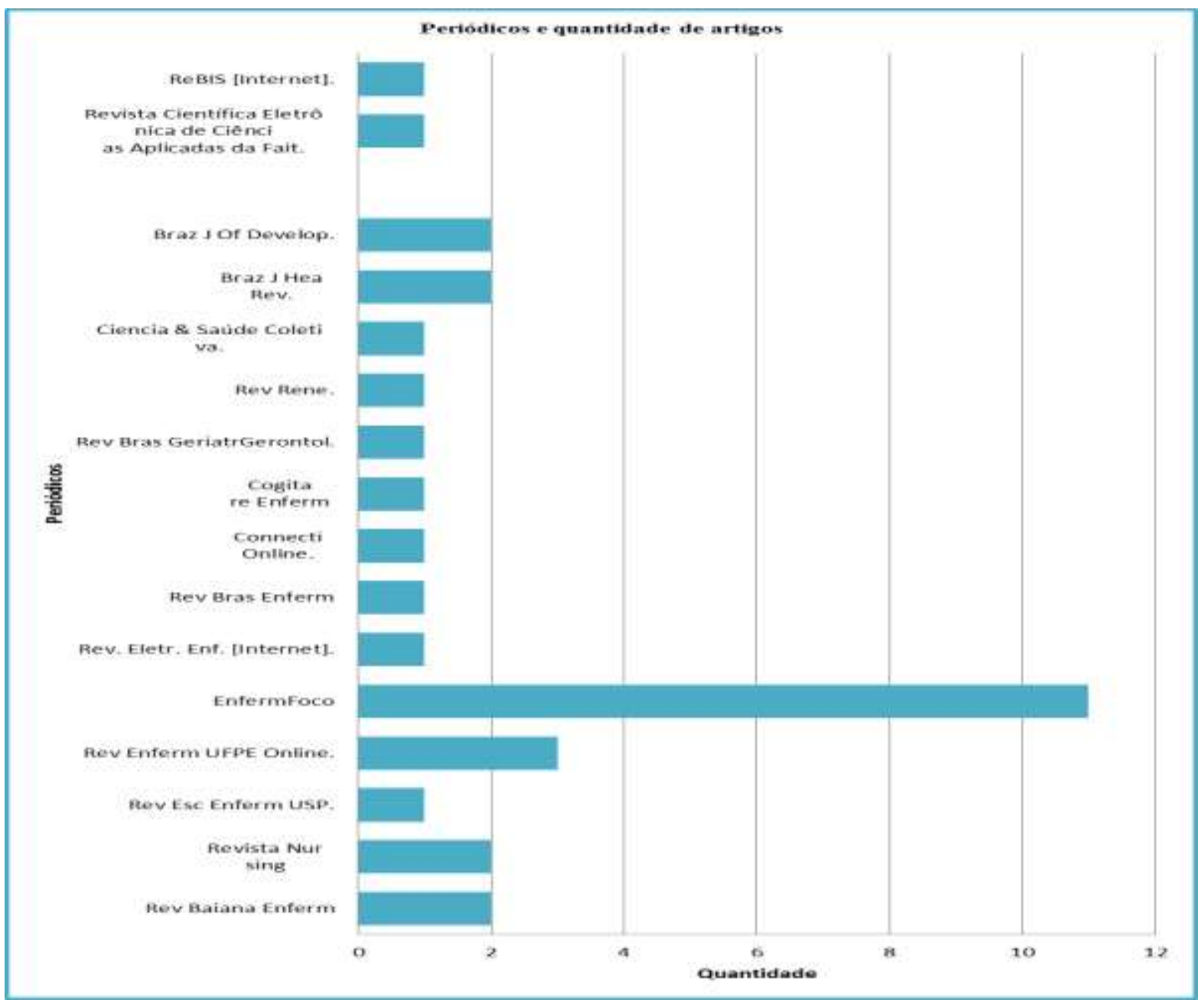

Fonte: Autores (2021). 
Segundo o gráfico ilustrado acima, pode-se observar quais são os periódicos e a quantidade de artigos que foram publicados de acordo com a amostra final do referido estudo. Dessa forma, verifica-se que na Rev Baiana de Enferm houve (2) publicações, Revista Nursing (2), Rev Esc Enferm USP (1), Rev Enferm UFPE (3), Enferm Foco (1), Rev Eletr Enf (Internet) (1), Rev Bras Enferm (2), Connecti Online (1), Cogitare Enferm (1), Rev Bras Geriatr Gerontol (1), Rev Rene (1), Ciência \& Saúde Coletiva (1), Braz J Hea Rev (2), Braz J of Develop (2), Portuguese Reon Facema (1), Revista Científica Eletrônica de Ciências Aplicadas da Fait (1), ReBIS (Internet) (1).

Gráfico 2. Distribuição conforme as bases de dados e a quantidade de artigos.

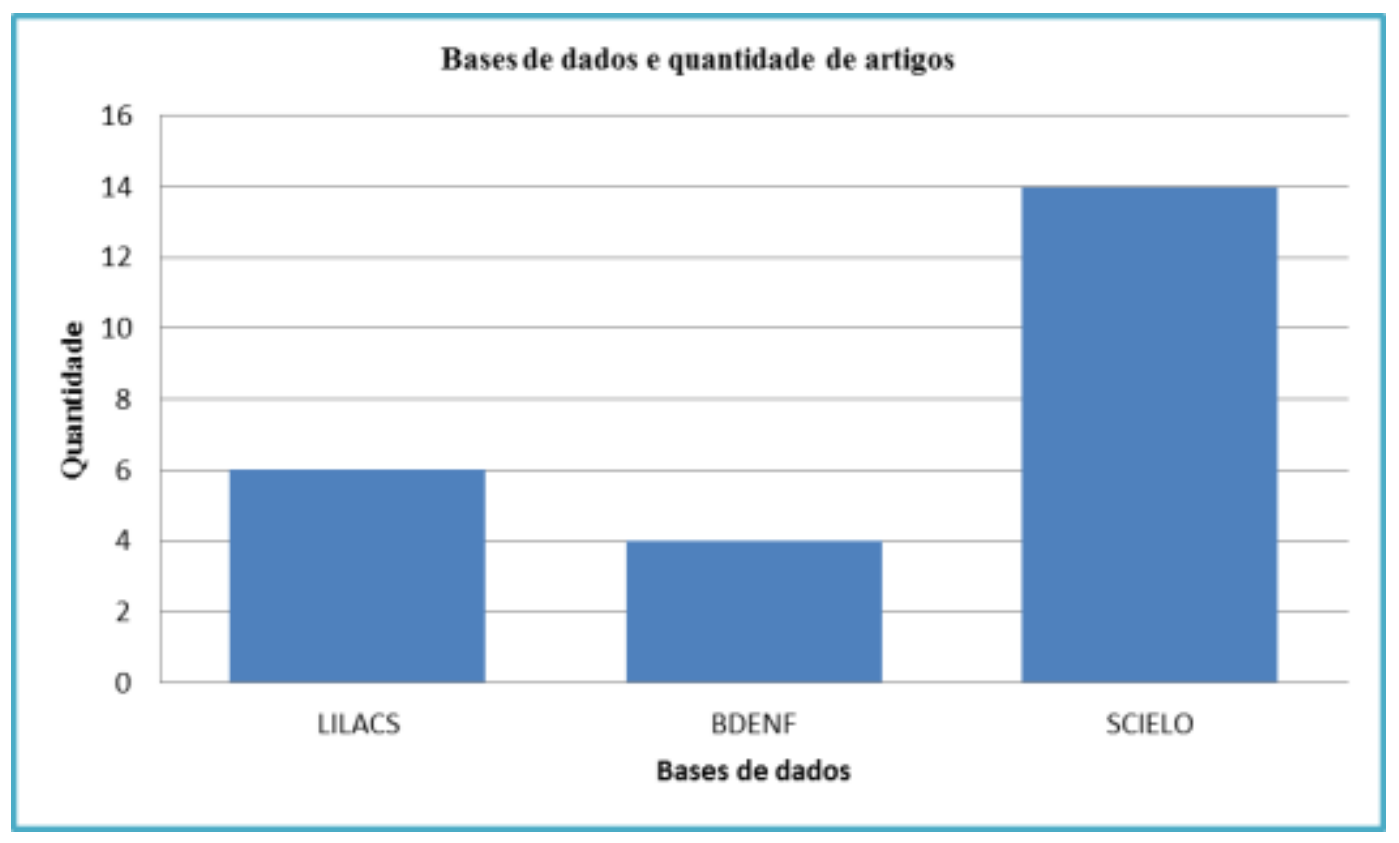

Fonte: Autores (2021).

De acordo com o gráfico representado acima, verifica-se as bases de dados e a quantidade de artigos publicados em cada uma. Nota-se que na LILACS ocorreu (6), publicações, BDENF (4), e na SCIELO (14). Desse modo, totalizando um resultado final de 24 artigos para serem trabalhados na conttrução do presente estudo.

Gráfico 3. Distribuição conforme as bases de dados e a porcentagem de artigos.

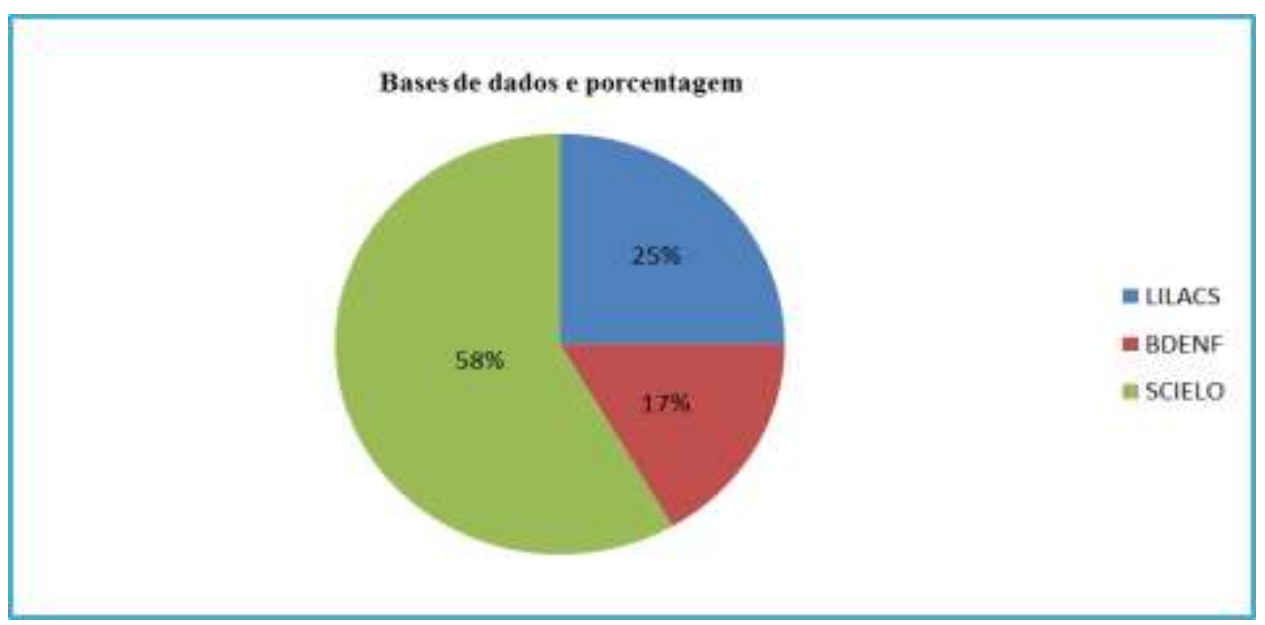

Fonte: Autores (2021). 
Ao observar o gráfico acima, percebe-se as bases de dados e a porcentagem de artigos publicados em cada uma, verifica-se que na LILACS ocorreu (25\%) das publicações, BDENF (17\%), e na SCIELO (58\%). Levando-se a um total geral de 24 artigos (100\%) dos artigos para serem explorados na elaboração do referido estudo.

Gráfico 4. Distribuição dos artigos conforme os anos de publicação e quantidade.

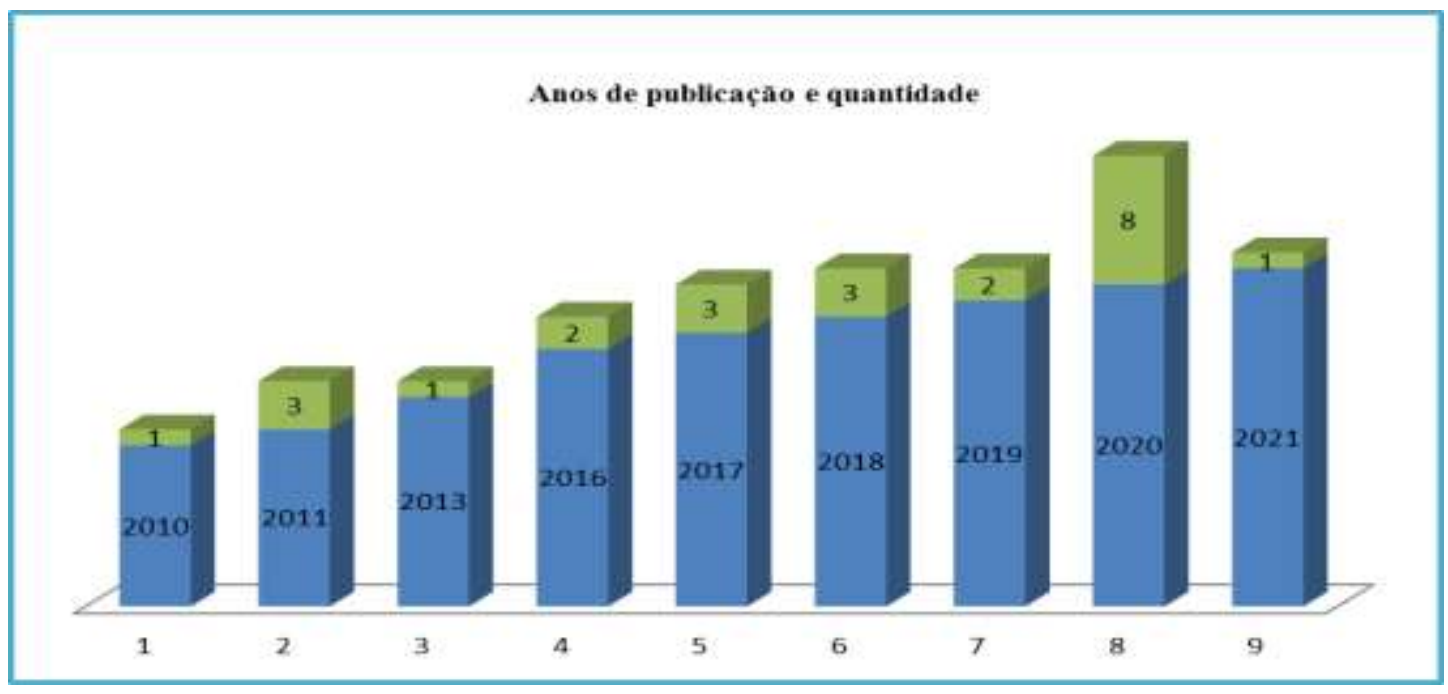

Fonte: Autores (2021).

Ao analisar o gráfico representado acima, identificam-se os anos de publicação e quantidade de artigos publicados. Nota-se que no ano de 2010 ocorreu (1) publicação, 2011 (3), 2013 (1), 2016 (2), 2017 (3), 2018 (3), 2019 (2), 2020 (8), 2021 (1). Nesse sentido, levando-se ao total final de 24 artigos para comporem a construção de presente estudo.

Gráfico 5. Distribuição dos artigos conforme ano de publicação e porcentagem.

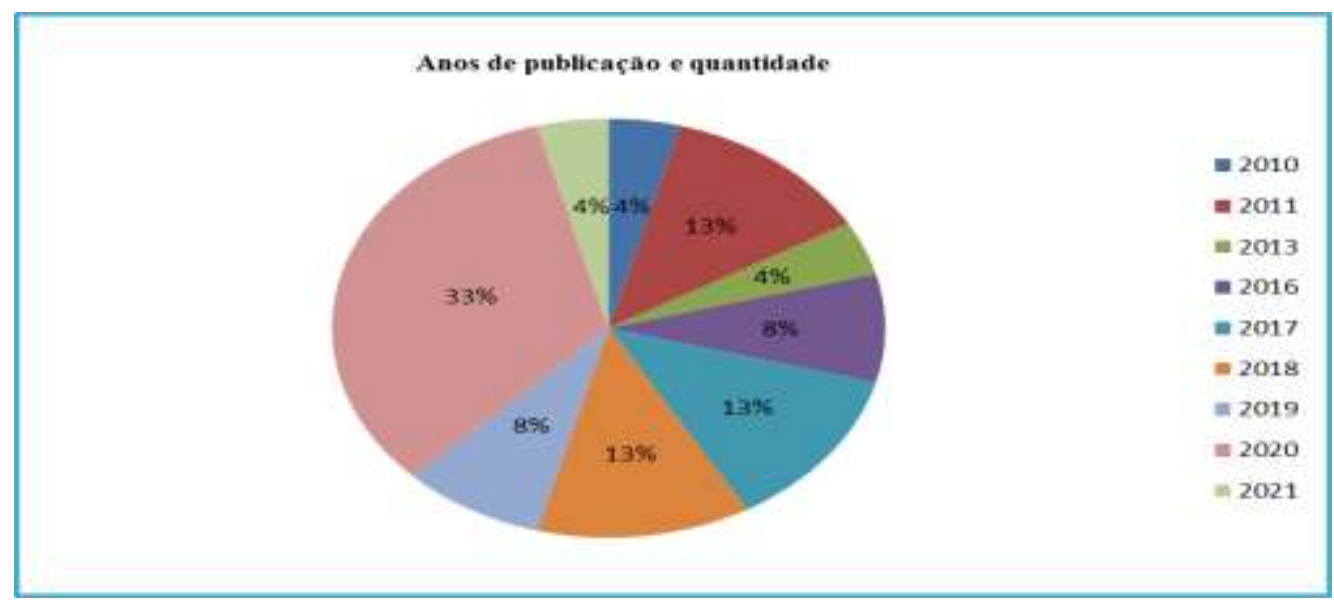

Fonte: Autores (2021).

Segundo o gráfico ilustrado acima, identifica-se os anos de publicação e a porcentagem de artigos encontrados. Constata-se que no ano de 2010 (4\%), 2011 (13\%), 2013 (3\%), 2016 (8\%), 2017 (2017\%), 2018 (13), 2019 (8\%), 2020 (33\%), 2021 (4\%). Dessa forma, nota-se que o ano de 2020 houve o maior número de publicações, sendo que, foram adotados os aspectos metodológicos dos critérios de inclusão e exclusão na elaboração do presente estudo.

A senescência, etapa natural do ciclo de vida humana, é caracterizada por mudanças físicas, biológicas e psicológicas. 
Nessa etapa da vida, um dos eventos que frequentemente impossibilitam o indivíduo de viver com autonomia é a fratura de algum segmento corporal decorrente de queda. Trata-se de um evento involuntário, originado, na maioria das vezes, na perda do equilíbrio. Salienta-se que as maiores taxas de ocorrência e de mortalidade por esta causa ocorrem em pessoas com mais de 60 anos. Contudo, tornar-se dependente de cuidados, ainda que temporariamente, reflete negativamente na qualidade de vida do idoso. Isto porque a queda, muitas vezes, ocorre em pessoas que até então eram totalmente independentes (Garollo et al., 2020).

$\mathrm{O}$ termo independência funcional está relacionado à mobilidade e capacidade funcional que permite ao indivíduo realizar Atividades da Vida Diária (AVD) com independência, indicando condições motoras e cognitivas adequadas para a execução das mesmas. A limitação para desenvolver tais atividades pode comprometer o dia a dia das pessoas, sobretudo de idosos, com implicação em risco de quedas, podendo ocasionar prejuízos irreparáveis à saúde, gerando incapacidades e até mesmo a morte. Assim, anualmente, aproximadamente de 30\% a 50\% dos idosos institucionalizados sofrem quedas e $40 \%$ deles experimentam quedas recorrentes. As quedas estão entre as principais causas de trauma entre idosos, sendo considerada a sexta causa de óbito por lesões acidentais e não acidentais. Após cair, o idoso pode sofrer várias consequências, como ferimentos graves, escoriações, arranhões e fraturas, o que pode contribuir para o declínio funcional na realização das AVD, isolamento social e maior vulnerabilidade para recorrência de quedas (Paula, Gonçalves, Nogueira, \& Delage, 2020.

Segundo Carvalho (2019), os enfermeiros realizam ações de cuidados, através do conhecimento dos fatores de riscos e da implementação das ações de prevenção para as quedas em idosos e ações de cuidados imediatos, entretanto não conhecem ou pouco utilizam ferramentas que padronizem as ações e auxiliem nos cuidados diários ao idoso com risco de quedas, bem como a notificação.

A etiologia das quedas pode ser variada. Os fatores podem estar relacionados à pessoa, como o uso de fármacos, o medo de cair, distúrbios na caminhada, redução das atividades da vida diária ou a fatores relacionados ao ambiente como tapetes soltos, diferenças de nível e pisos escorregadiços. Acredita-se ser essencial também identificar os fatores de risco extrínsecos de quedas em pacientes idosos com a finalidade de reconhecer precocemente os riscos existentes e, de imediato, eliminá-los ou diminuí-los utilizando medidas adequadas para a prevenção do incidente (Oliveira1 et al., 2018).

A prevenção de quedas está ligada diretamente ao cuidado com o paciente, principalmente, quando se trata da pessoa idosa, porque envolve conhecimentos, sentimentos, comportamentos e atitudes dos enfermeiros e equipe. Nesse sentido, a vigilância para a prevenção da ocorrência da queda deve ser também uma das prioridades da assistência de Enfermagem no momento da internação do paciente na instituição de saúde. A partir da identificação do risco da queda pelo enfermeiro, ele poderá formular um plano de ação e, posteriormente, avaliar os resultados da assistência prestada (Oliveira et al., 2017).

Para a formulação de um plano de cuidados consistente, o enfermeiro precisa conhecer os fatores que estão relacionados à ocorrência de quedas nos indivíduos idosos como fatores ambientais, cognitivos, fisiológicos, o uso de determinados medicamentos e a idade. Em busca da qualidade assistencial e, sobretudo, da segurança do paciente internado, faz-se necessário conhecer os fatores de risco aos quais os pacientes estão expostos, com o intuito de minimizar a ocorrência de quedas e de evitar as complicações decorrentes desse evento (Oliveira et al., 2017).

De acordo com Araújo, Martins, Lima, e Costa (2016), evitar o evento queda, assim como a preocupação na possibilidade de cair, atualmente é considerado uma conduta que requer o desenvolvimento de estratégias de prevenção, as quais são consideradas potencialmente úteis. Assim, atividades como melhorar a iluminação do ambiente, evitar tapetes soltos no domicílio e atentar para efeitos colaterais de diversas medicações são práticas que contribuem para a vigilância e prevenção de quedas.

A fragilidade dos idosos aliada a fatores extrínsecos, tais como má iluminação, piso escorregadio, fazem com que as quedas tenham consequências significativas na saúde física e psicológica dos mesmos, assim como podem repercutir na vida 
dos familiares. Ademais, esse agravo aumenta o risco de perda da independência e autonomia, institucionalização, eleva os custos com cuidados à saúde e a demanda por consumo de serviços especializados. Entre os principais fatores associados à mortalidade, após a ocorrência de quedas em idosos, estão a idade e as comorbidades, uma vez que o óbito não ocorre diretamente pela queda, mas por suas consequências (Abreu, Novaes, Oliveira, Mathias, \& Marcon, 2018).

O profissional de enfermagem, junto com a equipe multidisciplinar, deve ter a visão holística do paciente idoso, portanto o enfermeiro tem que observar o teórico e prático como analisar os fatores de risco para ter embasamento cientifico, como, na Atenção Básica de Saúde, projetar cuidados para cada caso desde orientações plano estratégico de ambiente seguro, utilização de dispositivos auxiliares, medicações utilizadas, analisar risco e beneficio entre diversas necessidades. Portanto a educação em saúde se for implantada poderá diminuir risco de quedas (Ferreira, \& Almeida, 2017).

Ao identificar os fatores de risco para quedas recorrentes, possibilita-se instituir medidas preventivas e, desta forma, reduzir os gastos públicos com internação e reabilitação. Diante deste panorama, pode-se dizer que o enfermeiro possui competência para criar planos de cuidados que envolvam medidas de prevenção aos fatores de risco, em atenção às quedas, baseado no vínculo com o idoso, familiares e cuidadores, gerenciando práticas educacionais para que sejam desenvolvidas na orientação quanto ao risco de quedas, bem como, aos seus familiares para preveni-las (Queiroz, Feitosa, Rodrigues, \& Sousa, 2020).

A adoção de medidas de prevenção são algumas estratégias que os idosos podem ter para evitar quedas, tais como, retirar tapetes e organizar os móveis no domicílio, a revisão no uso de medicamentos, utilizar óculos para correção da visão, deambular com órteses ou apoiar em corrimãos, evitar subir escadas, deixar os objetos do cotidiano acessíveis, entre outros. A realização dessas práticas de prevenção é explicada pelo fato deles já possuírem experiências anteriores com queda ou por conhecerem outros idosos que também já caíram. Os profissionais de saúde, em especial enfermeiros (as), devem incitar os idosos a desenvolverem aptidões para o autocuidado afim de, promover um envelhecimento saudável. Intervenções que buscam melhorar o conhecimento das pessoas sobre prevenção demonstram que ajudam a reduzir os episódios de quedas. Conhecer os fatores de risco, anteriormente apresentados, bem como suas consequências e medidas de prevenção, são de suma importância para desenvolver comportamentos de redução de riscos de queda. O principal papel do enfermeiro na prevenção de quedas é antecipar com ações e estratégias para minimizar ou até mesmo anular os riscos, levando sempre em conta as particularidades culturais e socioeconômicas de forma holística e humanizada (Queiroz, Feitosa, Rodrigues, \& Sousa, 2020).

Considerando a gravidade das consequências desse evento, há necessidade de programas eficazes de prevenção das quedas. Além destes, também é importante a implantação de programas de reabilitação após as quedas, com o objetivo de impedir ou minimizar a ocorrência de tais repercussões (Maia, Viana, Arantes, Alencar, 2011).

\section{Conclusão}

Evidenciou-se no estudo, que as necessidades de saúde da população idosa identificam-se de formas diversas, sendo que os principais problemas relacionados ao processo de envelhecimento são aqueles que comprometem a autonomia do idoso, uma vez que a diminuição da capacidade funcional favorece o declínio de suas capacidades físicas e mentais necessárias para a realização de atividades básicas na vida diária, bem como sua inclusão na sociedade, devido ao aumento do perfil de morbimortalidade nessa faixa etária. Nesse sentido, o envelhecimento populacional como realidade global, suscita nos serviços de saúde a necessidade da adoção de práticas promotoras de melhor qualidade de vida aos idosos. O fato de passarem abruptamente a necessitar de um cuidador não é uma condição aceita com facilidade.

Diante desse contexto, as quedas em pacientes idosos acarretam traumas físicos, psicológicos, perda de independência e até mesmo do risco de morte. Dessa forma, é imperativo que profissionais da Enfermagem tenham conhecimento dos fatores de risco para a ocorrência deste evento. Torna-se importante a realização de estudos futuros com a finalidade de ampliar a 
produção científica a respeito dessa temática tão relevante, sendo de suma importância, no sentido de aprofundar discussões que possam contribuir para a promoção da saúde e na melhoria da qualidade de vida desses pacientes.

\section{Referências}

Abreu, D. R. D. O. M., Novaes, E. S., Oliveira, R. R. D., Mathias, T. A. D. F., \& Marcon, S. S. (2018). Internação e mortalidade por quedas em idosos no Brasil: análise de tendência. Ciencia \& saude coletiva, 23, 1131-1141.

Almeida, M. M., Lima, M. M. A., Pessôa, R. M. C., \& Penha, A. S. (2018). Cuidados de enfermagem na promoção da segurança do idoso hospitalizado na prevenção de quedas. Revista Ciência \& Saberes-UniFacema, 3(4), 706-711.

Araújo, A. C. Q., Silva, V. A. D., Mota, R. S., Mendes, A. S., Barros, A. D. S., Sant'Anna, M. V., ... \& Santos, K. R. D. (2020). Incidentes relacionados à assistência à saúde em idosos hospitalizados. Rev. enferm. UFPE on line, 1-9.

Araújo, E. C., Martins, K. P., Lima, R. J., \& Costa, K. N. D. F. M. (2016). Preocupação com quedas em pessoas idosas atendidas em um Centro de Atenção Integral. Revista Eletrônica de Enfermagem, 18.

Augusto, C. A., Souza, J. P. D., Dellagnelo, E. H. L., \& Cario, S. A. F. (2013). Pesquisa Qualitativa: rigor metodológico no tratamento da teoria dos custos de transação em artigos apresentados nos congressos da Sober (2007-2011). Revista de Economia e Sociologia Rural, 51 (4), 745-764.

Baixinho, C. L., \& dos Anjos Dixe, M. (2020). Quais as práticas dos cuidadores para prevenir as quedas nos idosos institucionalizados? Revista Baiana de Enfermagem34,.

Botelho, L. L. R., de Almeida Cunha, C. C., \& Macedo, M. (2011). O método da revisão integrativa nos estudos organizacionais. Gestão e sociedade, 5(11), $121-136$.

Carvalho, A. A., Locks, M. O. H., Santos, S. A. D., Alvarez, A. M., Hammerschmidt, K. S. D. A., Schier, J. S., \& Fernandez, D. L. R. (2019). Evento quedas: cuidados de enfermagem para a segurança do idoso hospitalizado. Enferm. foco (Brasília), 105-110.

Costa, J. L., Arruda, G. T., do Nascimento Petter, G., \& Pivetta, H. M. F. (2021). Risco de quedas de idosas fisicamente ativas. Brazilian Journal of Development, 7(1), 6028-6037.

Ercole, F. F., Melo, L. D., \& Alcoforado, C. L. G. C. (2014). Revisão integrativa versus revisão sistemática. Rev Min Enferm, 18(1), 9-12.

Feliciani, A. M., Santos, S. S. C., \& Valcarenghi, R. V. (2011). Funcionalidade e quedas em idosos institucionalizados: propostas de ações de enfermagem. Cogitare Enfermagem, 16(4).

Ferenhof, H. A., \& Fernandes, R. F. (2016). Desmistificando a revisão de literatura como base para redação científica: método SSF. Revista ACB, 21(3), 550563.

Ferreira, D. C. D. O., \& Yoshitome, A. Y. (2010). Prevalência e caraterísticas das quedas de idosos institucionalizados. Revista Brasileira de Enfermagem, 63(6), 991-997.

Ferreira, M. E. A. D. C., \& Almeida, M. C. D. Risco de queda em idosos: atuação da enfermagem na prevenção.

Freire, H. S. D. S., Barbosa, I. L., Diniz, A. D. C., Silva, L. S. D., Djoco, E., \& Brasil, B. M. B. L. (2018). Conhecimento dos cuidadores de idosos institucionalizados sobre prevenção de quedas em Fortaleza-CE. Nursing (Säo Paulo), 2248-2253.

Freitas, R. D., Santos, S. S. C., Hammerschmidt, K. S. D. A., Silva, M. E. D., \& Pelzer, M. T. (2011). Cuidado de enfermagem para prevenção de quedas em idosos: proposta para ação. Revista Brasileira de enfermagem, 64(3), 478-485.

Garcia, S. M., Aristela, C., Grassi, L. T., de Araujo, C. C., Hartwig, S. V., \& Valadares, T. A. B. (2020). Educação em saúde na prevenção de quedas em idosos. Brazilian Journal of Development, 6(7), 48973-48981.

Garollo, C. M., Marcon, S. S., Teston, E. F., Barbosa, H. C. B., da Costa, J. R., Back, I. R., \& Ferreira, P. C. (2020). Cuidado e recuperação do idoso com fratura decorrente de queda na perspectiva do cuidador familiar. Revista Baiana de Enfermagem 34 ,.

Horta, H. H. L., de Faria, N. A., \& Fernandes, P. A. (2016). Quedas em idosos: assistência de enfermagem na prevenção. Connection line-revista eletrônica do UNIVAG, (14)

Maia, B. C., Viana, P. S., Arantes, P. M. M., \& Alencar, M. A. (2011). Consequências das quedas em idosos vivendo na comunidade. Revista Brasileira de Geriatria e Gerontologia, 14(2), 381-393.

Mendes, K. D. S., Silveira, R. C. D. C. P., \& Galvão, C. M. (2008). Revisão integrativa: método de pesquisa para a incorporação de evidências na saúde e na enfermagem. Texto \& contexto enfermagem, 17(4), 758-764.

Oliveira, D. U. (2017). Avaliação de quedas em idosos hospitalizados.

Oliveira, J. D. S., Diniz, M. M. P., Falcão, R. M. D. M., Chaves, B. J. P., Souza, S. V. O. D., Fernandes, A. M., \& Bezerra, S. C. A. (2018). Fatores extrínsecos para risco de quedas de idosos hospitalizados. Rev. enferm. UFPE on line, 1835-1840.

Oliveira, S. L. F., de Jesus Francisco, T., Santos, H. M., Cesar, A. N., \& de Lima, P. R. (2019). Fatores de risco para quedas em idosos no domicilio: um olhar para a prevenção. Brazilian Journal of Health Review, 2(3), 1568-1595. 
Research, Society and Development, v. 10, n. 3, e57110313369, 2021

(CC BY 4.0) | ISSN 2525-3409 | DOI: http://dx.doi.org/10.33448/rsd-v10i3.13369

Paula, J. G. F. D., Gonçalves, L. H. T., Nogueira, L. M. V., \& Delage, P. E. G. A. (2020). Correlação entre independência funcional e risco de quedas em idosos de três instituições de longa permanência. Revista da Escola de Enfermagem da USP, 54.

Pereira, A. S., Shitsuka, D. M., Parreira, F. J., \& Shitsuka, R. (2018). Metodologia da pesquisa científica.

Pereira, E. D. S., Sá, S. P. C., Napoleão, A. A., \& Cavalcanti, A. C. D. (2020). Intervenções de enfermagem ao idoso hospitalizado com risco de queda. Nursing (Säo Paulo), 4205-4212.

Queiroz, A. C. C. N., dos Santos Feitosa, C. O. P., de Moura Rodrigues, G. M., \& da Costa Sousa, J. (2020). Intervenções na prevenção de quedas de idosos em ambiente domiciliar. Revista Brasileira Interdisciplinar de Saúde.

Soares, C. B., Hoga, L. A. K., Peduzzi, M., Sangaleti, C., Yonekura, T., \& Silva, D. R. A. D. (2014). Revisão integrativa: conceitos e métodos utilizados na enfermagem. Revista da Escola de Enfermagem da USP, 48(2), 335-345.

Sousa Costa, A. G., de Araujo, T. L., de Souza Oliveira, A. R., Morais, H. C. C., da Silva, V. M., \& de Oliveira Lopes, M. V. (2013). Fatores de risco para quedas em idosos. Rev Rene, 14(4), 821-828.

Sousa, L. M. M., Marques-Vieira, C. M. A., Severino, S. S. P., \& Antunes, A. V. (2017). A metodologia de revisão integrativa da literatura em enfermagem. No21 Série 2-Novembro 2017, 17.

Souza, C. D., Fontana, R. T., Rodrigues, F. C. P., Meneghete, M. C., da Silva Copetti, T., Lazarotto, M. S., \& Bittencourt, V. L. L. (2020). Concepções da equipe de enfermagem sobre a prevenção de quedas em ambiente hospitalar. Brazilian Journal of Health Review, 3(4), 8341-8356.

Souza, M. T. D., Silva, M. D. D., \& Carvalho, R. D. (2010). Revisão integrativa: o que é e como fazer. Einstein, 8(1), 102-106. 